\title{
Dislocation focus construction in Chinese
}

\author{
Lawrence Yam-Leung Cheung
}

Received: 14 February 2008 / Accepted: 14 May 2009 / Published online: 14 August 2009

(C) The Authors(s) 2009. This article is published with open access at Springerlink.com

\begin{abstract}
The use of the Dislocation Focus Construction (DFC) (also known as "Right Dislocation") in colloquial Chinese (including Cantonese and Mandarin) gives rise to various non-canonical word orders. In DFCs, the sentence particle (SP) occurs in a sentence-medial position. The pre- and post-SP materials are demonstrated to be syntactically connected, based on four diagnostic tests, namely (i) the zinghai 'only' test, (ii) the doudai ("wh-the-hell") test, (iii) polarity item licensing, and (iv) Principle $\mathrm{C}$ violations. The findings offer new insights into the syntax of the Chinese left periphery and constraints on focus movement. First, the observations entail that Chinese CPs are head-initial, and an XP is obligatorily moved around the SP to a position higher than the CP. Second, the XP-raising in the DFC is argued to be driven by focus because of the focus interpretation induced. It is discovered that the focus movement is subject to the Spine Constraint, which turns out to be remarkably similar to the properties of the Nuclear Stress Rule (e.g., selection of focus set and metrical invisibility). It is argued that the DFC is the syntactic realization of the rule.
\end{abstract}

Keywords Dislocation - Focus movement - Sentence particle .

Head-initial CP · Word order · Nuclear stress rule · Cantonese · Mandarin

\section{Introduction}

The Dislocation Focus Construction (DFC), also known as "right dislocation" and "afterthought construction", has been noted in Mandarin Chinese (Chao 1968; Lu 1980; Packard and Shi 1986, among others), Cantonese (Siu 1986; Cheung 1997) and

L. Y.-L. Cheung ( $ه)$

Department of Linguistics, University of California,

3125 Campbell Hall, Los Angeles,

CA 90095-1543, USA

e-mail: yllc@ucla.edu 
Classical Chinese (Chen 1995; Yang and Yang 2002). Though generally not accepted in written form in Mandarin and Cantonese, DFCs often occur in spontaneous speech. ${ }^{1}$
a. Loeng
go zungtau
two
$\mathrm{Cl}$ hour
SP he leave-Perf
laa3 keoi zau-zo. ${ }^{2}$
"He has left for two hours."
b. Lai-le
ma, ni gege?
come-Perf Q you elder.brother
'Has your brother come?'
c. Junzi zai, ruo ren!
man-of-integrity SP Dem man
'That guy is a man of great integrity!'
(Cantonese/Cheung 1997)
(Mandarin/Lu 1980)
(Classical Chinese/Chen 1995)

Despite the relatively rigid word order in Chinese, the DFC gives rise to an inverted word order. Compare the DFC sentences in (1) and the canonical word order (CWO) sentences in (2). Notice the displacement of the underlined parts. The counterpart sentences in (2) are by and large synonymous.
a. Keoi zau-zo loeng go zungtau laa3. he leave-Perf two $\mathrm{Cl}$ hour SP "He has left for two hours."
b. Ni gege lai-le ma? you elder.brother come-Perf Q 'Has your brother come?'
c. Ruo ren, junzi zai!
Dem man man-of-integrity SP
'That guy is a man of great integrity!'

(Cantonese)

(Mandarin)

The comma in the representation of the DFC sentence is inserted for the ease of identification of the dislocated part, rather than for signaling a pause. In fact, $\mathrm{Lu}$ (1980) and Liang (2002, p. 76) claim that there is usually no pause at the comma position in Mandarin and Cantonese respectively. ${ }^{3}$ Prosodically, the part that comes

\footnotetext{
www.linguistics.ucla.edu/people/grads/yllc/dislocation.html. ping.php). Here is the list of abbreviations used in the glosses:

$\begin{array}{llll}\text { Acc } & \text { Accusative } & \mathrm{Cl} & \text { Classifier } \\ \text { Comp Complementizer } & \text { Dem } & \text { Demonstrative } \\ \text { GE } & \text { Possessive marker } & \text { Nom } & \text { Nominative }\end{array}$

NSFP Non-sentence-final particle (e.g., topic/phrase particle)

Perf Perfective marker Prog Progressive marker

Q Question particle $\quad \mathrm{Sg} \quad$ Singular

SP Sentence particle
}

${ }^{1}$ Some audio samples of the DFC taken from spontaneous speech can be found on the web at: http://

${ }^{2}$ LSHK Jyutping is used in the romanization of Cantonese sentences (http://lshk.ctl.cityu.edu.hk/Jyut-

As many Cantonese SPs and NSFPs differ minimally by tones, the romanization of all these Cantonese particles is marked with a tone number.

3 This contrasts with topicalization in Chinese in which the topic phrase is usually followed by an optional topic particle and a slight pause. 
after the sentence particle (SP) is mostly unstressed and uttered at a faster tempo than the pre-SP part in the Cantonese and Mandarin DFC. An anonymous reviewer of this paper also notes that the tone of the post-SP part must stay low.

The present paper discusses the derivation of the DFC word order and the associated constraints in relation to focus. Importantly, the DFC provides important information relating to two broad issues, namely, the head directionality of the Chinese $\mathrm{CP}$ and constraints on focus movement. First, to the best of my knowledge, the DFC is the only construction in Chinese in which sentence particles (henceforth 'SPs') appear in a non-final position. The patterns observed provide compelling evidence in support of the head-initial hypothesis of CPs in Chinese previously explored by Simpson and Wu (2002) and Hsieh and Sybesma (2008) among others. The idea in these works and the present paper is that CPs hosting SPs are headinitial, and sentences containing SPs in Chinese necessarily involve XP-raising around the SP to a higher position prior to Spell-Out. Second, it is found that the $\mathrm{XP}$-raising in DFCs is subject to a peculiar constraint which coincides remarkably with the focus projection rule, which was originally formulated to relate stress assignment and focus interpretation (Cinque 1993; Reinhart 1995; Zubizarreta 1998, among others).

The rest of the paper is organized as follows. Section 2 introduces the basic properties of the DFC. Section 3 talks about how the DFC sheds new light on the debate of the head directionality of Chinese CPs. Empirical findings are presented to support the proposal of head-initial Chinese CPs. Section 4 provides an analysis of the XP-raising necessitated by the head-initial CP structure. Special attention is paid to the Spine Constraint which governs and restricts syntactic movement and focus interpretation in DFCs. The conclusions of the paper are presented in Sect. 5.

\section{Basic properties of the DFC}

\subsection{Three major parts}

Descriptively, the DFC can be divided into three parts, including the pre-SP part, the post-SP part, and the SP. A characteristic feature of the DFC is that part of the sentence occurs to the right of the SP. The examples in $(3 b-d)$ illustrate the three parts. The corresponding canonical word order (henceforth 'CWO') sentence is included as (3a) for reference. In this paper, I will refer to the pre-SP string and the post-SP string the $\beta$-part and the $\alpha$-part, respectively, as in Cheung (1997) and illustrated in the Cantonese sentences in (3).

(3) a. Keoi wui maai jat bou dinnou aa3. he will buy one $\mathrm{Cl}$ computer SP

(CWO)

'He will buy a computer.' 


$\overbrace{\text { Wui maai jat bou dinnou }}^{\begin{array}{c}\text { Pre-SP part or } \beta \text { part } \\ (=I P)\end{array}} \begin{aligned} & \text { aa3 }, \overbrace{\text { keoi }}^{S P} \\ & \text { will buy one } \mathrm{Cl} \text { computer }\end{aligned}$

c.

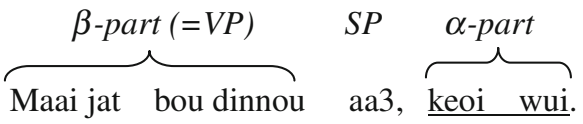

buy one $\mathrm{Cl}$ computer $\mathrm{SP}$ he will

d.

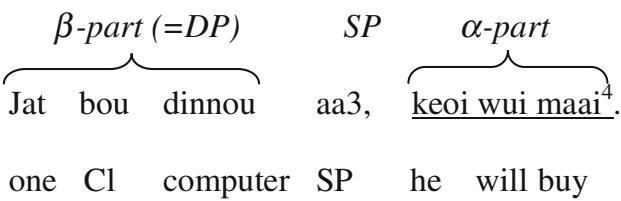

The $\alpha$-part usually looks like a remnant, for example, (3c) and (3d). The $\beta$-part is a constituent of different potential sizes. In $(3 b-d)$, the $\beta$-parts are an IP, VP and DP respectively. Examples (4)-(6) below show that the $\beta$-part (i.e., the underlined part) can be of other categories too.

(4) Hou hongoi lo1, go go sailouzai. (AP/Adjectival predicate) very lovely SP Dem $\mathrm{Cl}$ kid

'The kid is lovely.'

(5) Houzoi siufongjyun lei dak zou zaa3, go coeng fo. (IP) fortunate fireman come dak early SP Dem $\mathrm{Cl}$ fire

'As for the fire [topic], it is fortunate that the firemen came early.'

\begin{tabular}{llllllll} 
Bou dinsigei & hai & geido & cin & lo1, keoi man ngo. \\
\hline $\mathrm{Cl}$ & $\mathrm{TV}$ & be & how.much money & SP & he & ask & me
\end{tabular}
'He asked me how much the TV was.'

The above observations raise the question: what is the syntactic structure involved that makes the word order possible?

\subsection{Sentence particles in the DFC}

The hypothesis of this paper will be that SPs in DFCs (and elsewhere) are not basegenerated in sentence-final positions but are actually the heads of a head-initial CP

\footnotetext{
4 A reviewer of the paper and the native speakers s/he consulted found (3d) ungrammatical. However, other native speakers and I find it fully acceptable. The low acceptability could be attributed to two factors. First, the DFC is more acceptable when the $\beta$-part is heavy (see Sect. 2.4 for the heaviness condition). Since the $\beta$-part in (3d) is relatively not as heavy, it may degrade the acceptability. Second, it is true that (3d) is weird if uttered without a context. However, if it is preceded by the question: "What will he buy?", the sentence becomes much more acceptable. This is related to the focus interpretation of the DFC as discussed in Sect. 2.3.
} 
phrase. In working towards such a conclusion, a natural first question to ask is whether the particles present in sentence-medial position in DFCs are indeed the same elements as the SPs which regularly occur in surface sentence-final positions in CWO sentences. SPs are elements in Chinese that convey various communicative functions and speaker attitudes, e.g., assertion, question, evidential, etc. ${ }^{5}$ (Li and Thompson 1981). In speech, Chinese utterances often end with an SP. ${ }^{6}$ Since they normally occur at the end of an utterance, they are often referred to as "sentence final particles." This makes the sentence-medial distribution of the SP in the DFC rather unusual. Since Chinese also has some non-sentence-final particles (henceforth 'NSFPs') that mark the right edge of topics or subordinate clauses (Matthews and Yip 1994; Leung 2005), is it possible that the particles in DFCs might be phrasal particles? Several pieces of evidence below show that the sentence-medial particles in DFCs in fact pattern with sentence-final SPs in CWO sentences and hence are not to be categorized as NSFPs.

Leung (2005) exhaustively documents 80 SPs (including SP clusters) and 8 NSFPs in Cantonese. Although there is some overlap between the two sets, in general SPs cannot function as NSFPs. (7) is an example adapted from Leung (2005). While the NSFP ze1 can mark the end of the 'though' clause, the SPs, gwaa3 (expressing uncertainty), and lol (signaling the obviousness of the statement) cannot.

(7) Seoijin nei gam waa $\{$ ze1 $/ *$ gwaa3 $/ * 101\}$, jandei though you so say NSFP/SP/ SP others seon-m-seon zi dak gaak3?

believe-not-believe ZI can SP

'Despite what you said, do others really think so?'

In DFCs, all SPs typically found at the end of CWO sentences may occur as particles between the $\beta$ - and $\alpha$-parts of DFCs even though this is a non-sentencefinal position. This is illustrated in (8) with both gwaa3 and lo1.

(8) Hoi saam go wui $\{$ gwaa3 /lo1 $\}$, keoi gamjat.
open three $\mathrm{Cl}$ meeting SP / SP he today
'He had three meetings today.'

\footnotetext{
5 The following are some examples of SPs with different discourse functions.

a. (i) Keoi wui heoi Dolundo aa3. he will go Toronto SP

'He will go to Toronto.'

b. (ii) Zoengsaam zau-zo wo3.

Zoengsaam leave-Perf SP

'(Someone said) Zoengsaam left.'

c. (iii) $\mathrm{Ni}$ xihuan shenme yinyue ne? you like what music SP

(Cantonese/assertion) 'What kind of music do you like?'

${ }^{6}$ Not all Mandarin or Cantonese sentences end with an SP. In such cases, I assume that there is actually a silent SP.
} 
In other words, the range of particles found in sentence-medial positions in DFCs coincides exactly with the set of regular sentence-final SPs.

Second, Leung also notes that particle clusters are possible only with SPs but not with NSFPs. Some examples of sentence-final particle clusters are aal maa3 (expressing obviousness) and gaa3 laa3 bo3 (signaling a reminder). In DFC sentences, particle clusters are also found to be fully acceptable. Furthermore, the order of the particles must be the same as the sequencing which occurs in CWO sentences. As in CWO sentences, the cluster also cannot be broken up.

(9) Daa dinwaa bei keoi \{aa1 maa1/gaa3 laa3 bo3\}, John jiu. hit phone give he SP SP SP SP SP John have.to 'John has to give him a call.'

Finally, it can be noted that it is not possible to put an SP at the very end of a DFC sentence. This contrasts with CWO sentences, where the use of an NSFP does not preclude the occurrence of an SP at the end. Such a patterning has already been shown in (7), where zel (NSFP) and gaak3 (SP) co-exist in the same sentence. This option of adding an SP in linear sentence-final position is unavailable in DFCs as illustrated in (10) and (11) below. ${ }^{7}$

*Hoi saam go wui \{gwaa3/lo1\}, keoi gamjat aa1 maa3.
open three Cl meeting SP / SP he today SP SP
'He had three meetings today,

'He had three meetings today.'

(11) *Daa dinwaa bei keoi $\{$ aal maa1/gaa3 laa3 bo3\}, John
hit phone give he SP SP SP SP SP John
jiu $\quad$ lo1.
have.to SP
'John has to give him a call.'

\footnotetext{
${ }^{7}$ It should be noted that native speakers may find (10) and (11) not too bad or even acceptable. This claim might be further challenged by examples such as (i), which seems to me perfect and has a particle gaa3 at the very end:

(i) Jat bou dinnou lo1, keoi hoji maai gaa3. one $\mathrm{Cl}$ computer $\mathrm{SP}$ he can buy SP

'A computer! He can buy [it].'

Though the occurrence of gaa 3 in (i) is acceptable, it is argued in Sect. 3.1 .2 that (i) (and (10) and (11) for some speakers) actually involves the juxtaposition of two independent utterances/fragments. Three tests are presented there to demonstrate that no syntactic connectivity exists between the pre- and post-lo1 parts of (i), and this contrasts very clearly with the positive existence of connectivity once the particle gaa3 is removed as in (ii) below, which is a genuine DFC.
}

(ii) Jat bou dinnou lo1, keoi zinghai hoji maai. one $\mathrm{Cl}$ computer SP he only can buy 'He can only buy a computer.' 


\subsection{Focus}

Cheung (1997) shows that in DFCs the $\beta$-part or a sub-part of it constitutes the informational focus ${ }^{8}$ of the sentence (in the sense of Kiss 1998) as illustrated in (12).

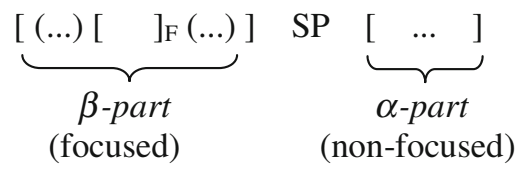

Question/answer pairs are used to diagnose for focus in this study. The assumption is that "the position of focus in an answer correlates with the questioned position in wh-questions" (Rooth 1996). When the DFC serves as an answer, the element corresponding to the $w h$-phrase must occur in the $\beta$-part and cannot be located in the $\alpha$-part. Consider Cantonese example (13) below.

(13) Question: What will he buy?

Answer:

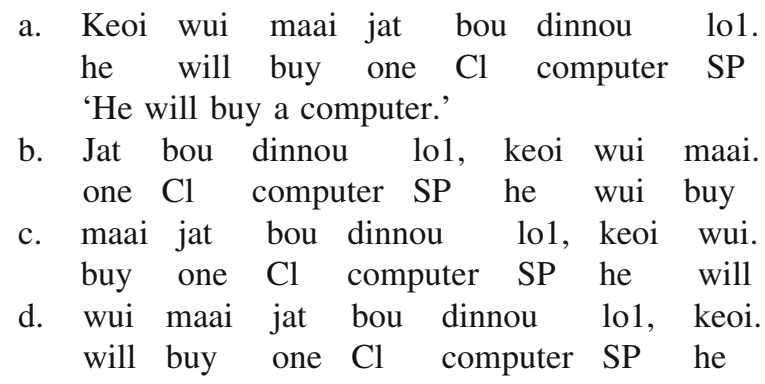

(CWO)

The object DP is questioned and therefore is the focus. In addition to the CWO sentence (13a), the DFC forms in (13b-d) are equally felicitous answers to the question because the answer "a computer" is contained in the $\beta$-part in all cases. It should be noted that the $\beta$-part does not necessarily correspond fully to the focused constituent and could be a larger phrase containing the focused constituent. For example, even though the $\beta$-parts in $(13 \mathrm{c}-\mathrm{d})$ are constituents which are larger than the questioned object DP, they are acceptable as answers to the question.

When the subject is questioned, the felicity of the DFC sentences changes in an interesting way. Consider the dialog in (14). (\# = infelicitous)

(14) Question: Who bought a computer?

Answer:

a. Keoi wui maai jat bou dinnou
he will buy one $\mathrm{Cl}$ computer
'He will buy a computer.'

(CWO)

\footnotetext{
8 Kiss (1998) distinguishes two types of focus, namely identificational versus informational focus. She characterizes informational focus as "new, nonpresupposed information marked by one or more pitch accents-without expressing exhaustive identification performed on a set of contextually or situationally given entities." The focus exhibited in the DFC clearly does not give rise to exhaustive identification reading.
} 


$\begin{array}{rlllllll}\text { b. \#Jat } & \text { bou } & \text { dinnou } & \text { lo1, } & \text { keoi } & \text { wui maai. } & \text { (DFC) } \\ \text { one } & \mathrm{Cl} & \text { computer } & \text { SP } & \text { he } & \text { wui } & \text { buy } & \\ \text { c. \#Maai } & \text { jat } & \text { bou } & \text { dinnou } & \text { lo1, } & \text { keoi } & \text { wui. } & \text { (DFC) } \\ \text { buy } & \text { one } & \mathrm{Cl} & \text { computer } & \text { SP } & \text { he } & \text { will } & \\ \text { d. \#Wui } & \text { maai } & \text { jat } & \text { bou } & \text { dinnou } & \text { lo1, } & \text { keoi. } & \text { (DFC) } \\ \text { will } & \text { buy } & \text { one } & \mathrm{Cl} & \text { computer } & \text { SP } & \text { he } & \end{array}$

Significantly, the DFC patterns in (14b-d) are no longer felicitous answers to the question in (14). Note that the subject DP keoi that corresponds to the wh-word does not reside in the $\beta$-part in $(14 b-d)$. Not being part of the focus domain (i.e., the $\beta$-part) in the DFC, the subject DP fails to be licensed as the focus, causing infelicity in the answer-form. This contrast present in (13) and (14) demonstrates that DFCs and CWO sentences differ importantly in information structure and the possible location of focus in the sentence. The $\beta$-internal focus structure motivated by such patterns receives further support from the patterning of emphatic stress in DFCs. A contrastive/emphatic stress is possible only in the $\beta$-part of DFCs and cannot occur in the $\alpha$-part.

\subsection{Heaviness condition}

A further well-formedness condition on DFCs is that native speakers tend to find DFC sentences with a heavy $\beta$-part more acceptable than those with a light $\beta$-part, and examples of DFCs which are commonly found in the literature regularly have heavy $\beta$-parts. I will refer to this effect as the 'heaviness condition'. In this regard, reconsider examples ( $3 b-d)$. While ( $3 b)$ can be easily uttered (and accepted) out of the blue, (3c) and (3d) with less heavy $\beta$-parts generally require more of a clear focus context to be licensed and would be appropriate responses to the question in (15).

$\begin{array}{llllll}\text { (15) Keoi } & \text { wui } & \text { zinghai maai matje aa3? } \\ \text { he } & \text { will } & \text { only } & \text { buy } & \text { what SP }\end{array}$

'What is the thing $x$ such that he will only buy $x$ ?'

\section{Head-initial Chinese CP and syntactic connectivity}

An important question concnering DFCs is how the word order in a DFC is derived. To answer this question, I would like to begin with a related question: how do the SPs in DFCs end up occurring in non-sentence-final positions? In Sect. 3.1, I first review arguments from other studies that SPs in Chinese are actually the heads of head-initial CPs. In Sect. 3.2, I show that the $\alpha$-part and the $\beta$-part are syntactically connected but are not two independent fragments and suggest that the special word order in DFCs is derived by moving an XP inside the IP to a position higher than the $\mathrm{SP}$, as shown in (16). 
(16)

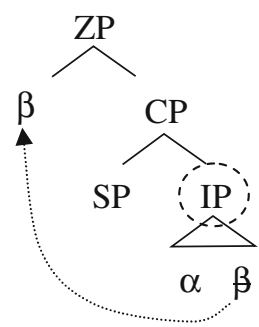

\subsection{Head-initial versus head-final}

Structurally, SPs in Chinese are often regarded as the heads of functional projections in the C domain (S.-P. Law 1990; Cheng 1991, 1994; Li 2006, among others). SPs characteristically take scope over the sentences they occur in and contribute to the encoding of speaker's attitude. Such observations go well with Rizzi's (1997) proposal of projections such as ForceP in the $\mathrm{C}$ domain that typically encode speaker attitudes and discourse functions. With regard to the head-initial versus head-final nature of $\mathrm{CP}$ in Chinese, until recently the discussion of the headdirectionality of $\mathrm{CP}$ in Chinese has been rather limited. In theory, there might seem to be two ways of modeling sentences with SPs, a head-final structure as in (17a) and a head-initial analysis incorporating IP-movement, as in (17b):

a. Head-final

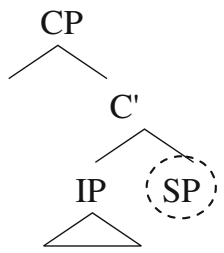

b. Head intial + IP movement

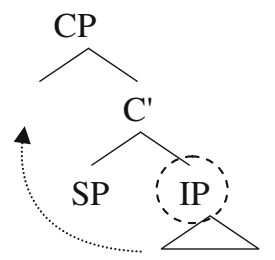

The head-final CP hypothesis (17a), adopted by S.-P. Law (1990) and A. Law (2003, 2004), has the merit of simplicity. As the SP consistently appears at the end of a sentence, (17a) offers a straightforward mapping onto the linear word order. Certain other studies (see Sect. 3.1.1), however, favor the head-initial CP hypothesis (Simpson and Wu 2002; Hsieh and Sybesma 2008). These authors suggest that the SP is generated to the left of the IP and that the IP is subsequently moved around the SP, resulting in the observed word order. Such analyses support Kayne's (1994) anti-symmetry claim of syntactic structure in Chinese and align CP with other head-initial categories in Chinese.

Although the head-initial analysis of CPs in Chinese is supported by certain theoretical and empirical evidence, it remains the subject of dispute, and many works continue to assume a head-final analysis of CPs. In order for the head-initial $\mathrm{CP}$ analysis to be significantly strengthened, a broader range of empirical evidence needs to be identified, and this is a primary goal of the present paper. The evidence presented from DFCs will be shown to add some significant new support for the 
head-initial CP analysis, and bear importantly on fundamental issues of basic word order $^{9}$ and clausal structure in Chinese. Before considering the contribution of DFCs to the head-final/head-initial debate, I will first briefly review arguments for the head-initial analysis of CPs in Chinese in previous studies.

\subsubsection{Previous head-initial CP analyses}

\section{Sybesma (1999)}

Sybesma (1999) presents two arguments for a head-initial analysis of CPs in Chinese, with IP movement into SpecCP. First, it is noted that a head-initial analysis of CP would theoretically accord with Kayne's theory of anti-symmetry. Second, it is claimed that IP movement may be required by aspects of the syntax of Chinese. In sentences with a final question particle, it is suggested that the interrogative $\mathrm{C}$ has certain features to be checked off, and this is achieved by moving an entire wh-expression structure containing the $w h$-variable and its associated Q-operator. Following Tsai (1994), Sybesma assumes that while the Q-operator in English is adjoined to the lexical projection containing the $w h$-variable, the Q-operator in Chinese is adjoined to the IP, which immediately contains the $w h$-variable. As a result, only the $w h$-phrase needs to be moved in English (18a) but the entire IP needs to move in Chinese (18b). Consequently, as a result of the IP-movement to SpecCP, the Q-particle in $\mathrm{C}^{0}$ occurs in surface sentence-final position in Chinese.

$$
\text { a. English }
$$

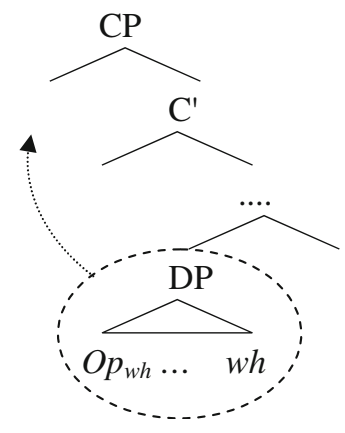

b. Chinese

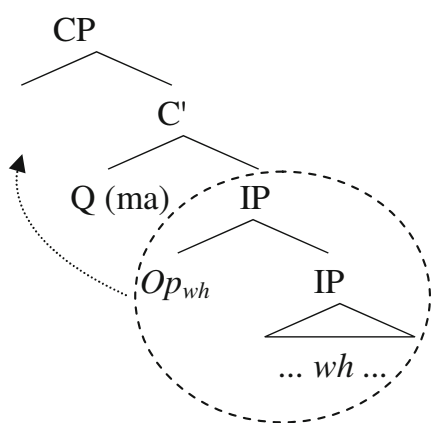

\section{Simpson and $W u(2002)$}

Simpson and $\mathrm{Wu}$ (2002) argues that the SP kong in Taiwanese is undergoing grammaticalization from a verb to a complementizer. The incomplete grammati-

\footnotetext{
${ }^{9}$ The basic word order of Chinese has been the subject of continual debate in the literature (e.g., Li and Thompson 1974; Sun and Givón 1985; Mulder and Sybesma 1992), as Chinese displays mixed features of $\mathrm{VO}$ and OV languages. On the one hand, the heads of phrases precede their complements in projections such as VP, PP, Classifier Phrase, etc. On the other hand, adjectival modification and relative clause are pre-nominal. Previous attempts such as Li (1990) have been made to resolve the apparent conflicts and analyze Chinese as a VO language.
} 
calization of the SP makes it possible to observe the occurrence of the SP in either the pre- or the post-clausal position, as in (19) and (20), respectively.

(19) A-hui siong kong A-sin $m$ lai. (=(36) in Simpson and Wu 2002) A-hui think KONG A-sin NEG come

'A-hui thought that A-sin was not coming.'

(20) A-hui siong A-sin NEG lai kong. (=(38) in Simpson and Wu 2002) A-hui think A-sin NEG come $\overline{\mathrm{KONG}}$

'A-hui thinks A-sin is not coming.'

Simpson and $\mathrm{Wu}$ argue that certain apparent violations of the tonal sandhi patterns of kong and the IP can be explained if the head-initial CP hypothesis and IP-movement analysis is adopted. Simpson and Wu (2002) offer two possible explanations for the IP movement. First, the SP might be an enclitic which demands phonological support from an element to its left. As a result, the IP movement is triggered to fulfill this requirement. Alternatively, the IP movement may occur as an operation of defocusing the IP and focusing of the SP. ${ }^{10}$

Apart from kong, Simpson and Wu further point out that in various C-initial structures in Mandarin, an overt element in $\mathrm{C}$ does indeed precede its complement IP. For example, elements such as ruguo 'if' or shuo (embedded complementizer) in $\mathrm{C}$ occur before IP.

Ta xiang $\left[\begin{array}{c}\mathrm{CP} \\ \text { shuo }\left[{ }_{\text {IP }} \ldots\right.\end{array}\right]$

he think say

'He thought that ....'

$$
\begin{aligned}
& \begin{array}{l}
\text { Ruguo mingtian } \\
\text { if } \\
\text { if }
\end{array} \text { tomorrow down } \\
& \text { 'If it rains tomorrow, ....' }
\end{aligned}
$$

Such patterns lead Simpson and Wu to conclude that Chinese CPs are consistently head-initial.

\section{Hsieh (2005) and Hsieh and Sybesma (2008)}

Hsieh (2005) and Hsieh and Sybesma (2008) also investigate the Taiwanese SP kong. They focus on the distribution of the complementizer kong and the homophonous SP kong. In their system, CP is divided into layers headed by different $C$ heads. What is important to these studies is the observation that the TP/ IP-clause can be "sandwiched" between two C heads, namely, the complementizer kong and the SP.

\footnotetext{
${ }^{10}$ Simpson and $\mathrm{Wu}$ (2002) point out that the IP-movement proposed in kong-sentences can be compared to the prosodically-driven p-movement suggested by Zubizarreta (1998) to occur in various Romance languages. For example, in Spanish, although the basic word order is SVO, the VO constituent can be moved before $\mathrm{S}$, resulting in VOS sequences, so that the VO is defocused and the $\mathrm{S}$, receives the nuclear stress and focus.
} 
(23)

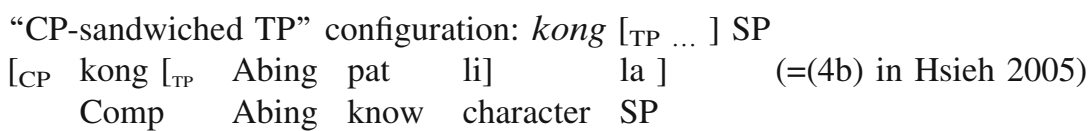
'(I am surprised that) Abing knows (how to read) Chinese characters!'

Hsieh and Sybesma consider in detail three possibilities in the derivation of CP-sandwiched TP word order, as given in (24).

a. Mixed direction

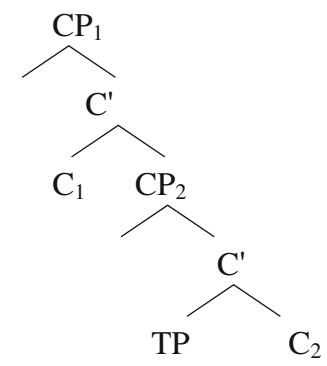

b. Head-final

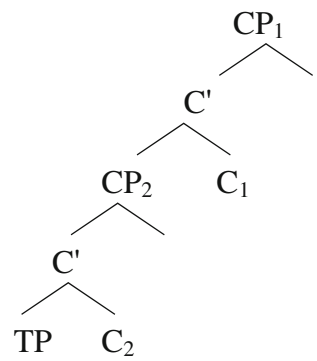

c. Head intial

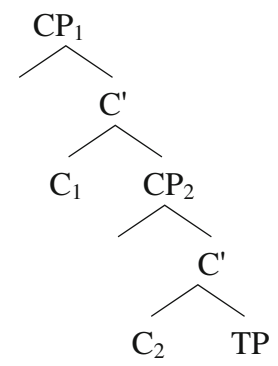

Mixed head-directionality (24a) is rejected because of the complexity of parameter setting and its challenge to language acquisition. Head-final CP structures (24b) are also discarded as inappropriate for the analysis of the structures considered as they claim that such structures would entail the occurrence of a range of violations of movement-related constraints. As a result, Hsieh and Sybesma pursue the headinitial CP hypothesis.

Unlike Simpson and Wu (2002), Hsieh and Sybesma suggest that it is a lower CP, not IP/TP, that gets moved, as illustrated in (25).

$$
\text { Head-initial: }\left[\mathrm{C}_{1}\left[\mathrm{C}_{2}[\mathrm{TP}]\right]\right] \rightarrow\left[\left[\left[\mathrm{C}_{2} \mathrm{TP}\right]_{\mathrm{i}} \mathrm{C}_{1}\right] t_{1}\right]
$$

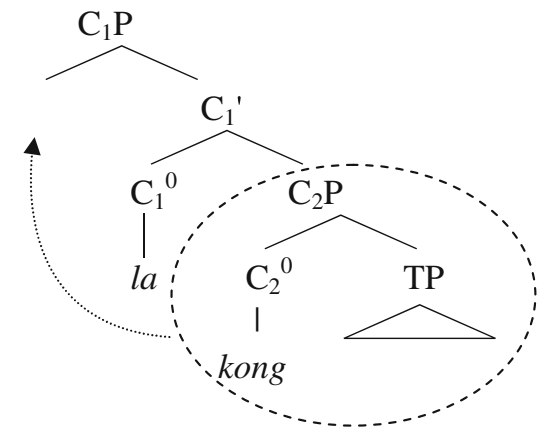

$\mathrm{C}_{2}{ }^{0}$ is taken to be the phase head in the sense of Chomsky (2001). On the basis of the Linear Correspondence Axiom (Kayne 1994), they assume that $\mathrm{C}_{2} \mathrm{P}$ has to enter into an asymmetric c-command relation with $\mathrm{C}_{1}{ }^{0}$ in order to linearize the structure in (25). In other words, it must be guaranteed that $\mathrm{C}_{1}{ }^{0}$ and $\mathrm{C}_{2} \mathrm{P}$ are not in a mutual c-command relation for linearization. Following Moro (2000), they claim that $\mathrm{C}_{2} \mathrm{P}$ 
moves to the left of $\mathrm{C}_{1}{ }^{0}$ as a last resort strategy to break the symmetry. Consequently, the sequence $\mathrm{C}_{2}{ }^{0} \mathrm{IP} \mathrm{C}_{1}{ }^{0}$ is derived.

The evidence offered by the studies above, however, has two limitations. First, the analyses capitalize on the distribution of a restricted number of particles such as the Q-particle ma, the SP kong, and the complementizer kong. It is questionable whether the analyses are in fact generalizable to the entire class of SPs, and Sybesma (1999) indeed admits difficulties in extending his analysis to non-interrogative sentences. The observations about the complementizer kong are very useful; yet the complementizer kong seems to be rather exceptional in its patterning as compared with other similar elements. Second, in the data available so far, the IP always occurs to the left of the SP in the surface word order. The range of good empirical evidence for the head-initial $\mathrm{CP}$ analysis needs to be expanded further for the hypothesis to be well-supported.

\subsubsection{New evidence for head-initial analysis}

Four structural hypotheses of the DFC are considered in this section, namely, leftward movement, rightward movement, a parallel structure analysis, and a fragment analysis. All can potentially derive the sequence " $\beta$ SP $\alpha$." The leftward movement proposal will be argued to be the most plausible one.

\section{Hypothesis 1: leftward movement}

In Cheung (2008), a leftward movement analysis, as schematized in (26), provides a simple account of why the pre-SP $\beta$-part is generally a constituent, the post-SP $\alpha$-part looks like a remnant, and the SP sits in-between. This analysis also guarantees that elements in the $\beta$-part are structurally in the scope of the $\alpha$-part before the movement of the $\beta$-part. Such a relation is crucial in the explanation of a range of syntactic dependencies.

\section{(26) Head-initial SP + leftward movement}

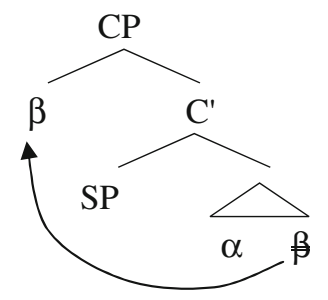

\section{Hypothesis 2: rightward movement}

The post-SP material could potentially be derived by adjoining the $\alpha$-part of the sentence to $\mathrm{CP}$, as in (27). In this case, the $\mathrm{CP}$ projection would be head-final. 


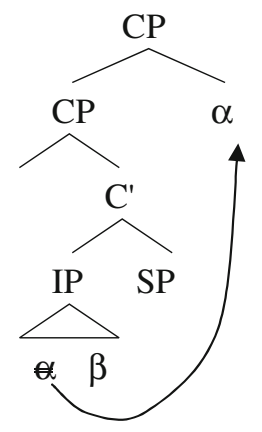

Such an analysis would suffer from two difficulties. First, rightward movement is generally not attested in Chinese. Second, even if rightward movement exists, as the $\alpha$-part is generally not a constituent, the movement rule has to be rather complicated. Consider (28).

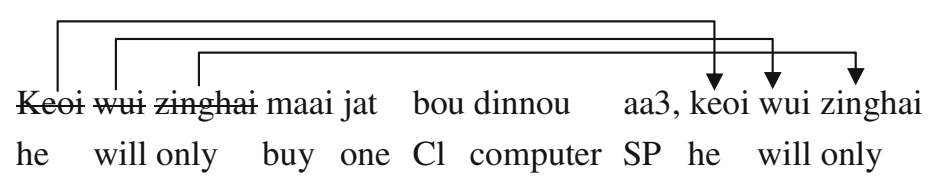

In (28), multiple rightward movements are needed to generate the linear word order. The movement is likely to involve both phrases (e.g., subject) and heads (e.g., wui 'will' and zinghai 'only'). Further, some mechanism is needed to guarantee that the words in the $\alpha$-part line up in the correct order. Alternatively, one may suggest that the $\beta$-part may first move out of the IP as a topic, followed by the rightward movement of the remnant IP. However, this strategy would necessitate additional assumptions and operations, e.g., both leftward and rightward movements. It will not be pursued further.

\section{Hypothesis 3: deletion of parallel structure}

DFCs could possibly be analyzed as two identical sentences, one being the copy of the other. For simplicity, let us assume that the two sentences are linked syntactically (dotted line). Some deletion mechanism guarantees the audible parts in the two sentences complement each other, as in (29), giving rise to the illusion of a single sentence.

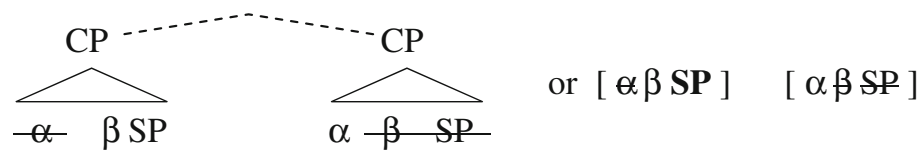

Such an idea is reminiscent of Nunes' (2004) scattered deletion of a chain link. His observation is that although economy considerations generally allow only one copy 
in a chain to be spelt out, partial deletion in principle can target multiple copies in a chain when the regular "full" deletion does not converge for independent reasons in linearization. This approach to analyzing DFCs, however, is untenable for several reasons. First, it is unclear why an identical copy of the sentence should be generated. Second, scattered deletion is available only when the spell-out of a full copy does not converge. Clearly, the full copy, $\alpha \beta \mathrm{SP}$, is a well-formed sentence. Scattered deletion should always be blocked. Third, additional assumptions must be stipulated to explain why the sequence $\alpha$ SP $\beta$ is generally bad, but $\beta$ SP $\alpha$ is fine. Last, a c-command dependency is widely observed between an element in the $\alpha$-part and the $\beta$-part of the DFC. Very often, these dependency relations are not available if the c-commanded element is elided or moved. (This point will be elaborated in Sect. 3.2.) The scattered deletion analysis runs into problems because it entails such illicit structures. Consider the example involving zinghai 'only.'

\begin{tabular}{|c|c|c|c|c|c|}
\hline Keoi zinghai & gindou & John aa3.] & [Keoi & zinghai & gindeu John at3.] \\
\hline only & see & John SP & he & only & John SP \\
\hline
\end{tabular}

Assume that scattered deletion is available and correctly deletes the relevant strings in the parallel structure in (30). The focus of zinghai 'only' is associated with the deleted VP. However, association with deleted material is generally prohibited (see Sect. 3.2.1).

\section{Hypothesis 4: paratactic fragment structure}

A fourth hypothesis for analyzing DFCs is that they involve two sentences. The part that comes after the SP is a (parenthetical) fragment, juxtaposed with a sentence, as shown in (31).

a. Main sentence

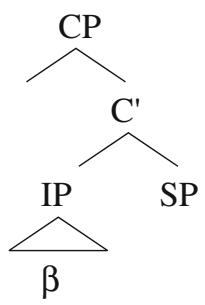

b. Fragment

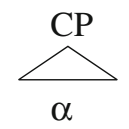

The two parts are not connected syntactically but are pragmatically related to each other. As paratactic parentheticals are possible in colloquial speech, the analysis is not implausible.

Nevertheless, the hypothesis is untenable for three reasons. First, similar to Hypothesis 3, (31) cannot explain why robust syntactic reconstruction effects between the $\alpha$-part and the $\beta$-part are possible across sentences (see Sect. 3.2). For example, on the parenthetical fragment account, the dependency between zinghai 'only' and John should be illicit. Nevertheless, (32) is a perfectly well-formed sentence. 

a. Main sentence
b. Fragment

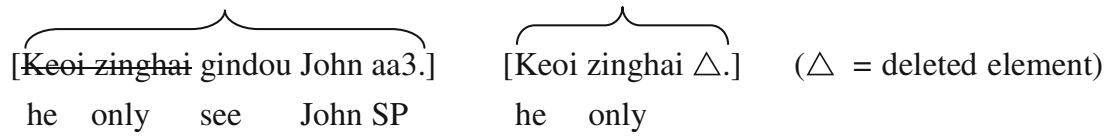

Second, it does not explain why it is not possible to have another SP at the right edge of the so-called "fragment" (see Sect. 2.2). Last, Potts $(2005,2007)$ argues that parentheticals and appositives generally do not contribute to the truth condition of the at-issue assertion. The falsity of a parenthetical does not seem to invalidate the main proposition of a sentence. However, if the information in the post-SP part (or so-called afterthought) of a DFC is incorrect, the truth value of the sentence can change. This shows that the $\alpha$-part has a different semantic contribution from parentheticals.

To sum up, out of the four hypotheses, Hypothesis 1 is the most plausible representation consistent with the properties of the DFC and current syntactic theory.

\subsection{Syntactic connectivity}

To substantiate Hypothesis 1 , it is necessary to show that that the $\alpha$-part and the $\beta$-part are the integral parts of a sentence, i.e., the two parts are syntactically connected. Several diagnostic tests will be presented to show the syntactic connectivity, namely (i) a zinghai 'only' test, (ii) a doudai ("wh-the-hell" adverb) test, (iii) the licensing of polarity item cungloi 'ever', and (iv) Principle C violations. The logic behind the four tests is the same. First, the test must involve a dependency relation between an element in the $\alpha$-part and another one in the $\beta$-part. The dependency can only be obtained when the one in the $\alpha$-part c-commands the other in the same sentence (Condition 1). Second, the dependency must also be shown independently to be impossible when the element being c-commanded is silent or deleted (Condition 2). Essentially, these conditions are set up such that these syntactic dependencies cannot hold across sentences and between deleted elements. This is especially crucial to refuting Hypotheses 3 and 4. It turns out that such dependency relations are indeed available in DFCs, which is consistent with Hypothesis 1.

\subsubsection{Zinghai 'only' test}

Like English only, the focus associated with zinghai 'only' in Cantonese can only be an element in its c-command scope (Condition 1). Take (33) as an example. Words in capital letters in the translation refer to the intended associated focus. The characterization correctly rules out reading (a) as the subject is not in the scope of the preverbal zinghai.

$$
\begin{array}{lllllll}
\text { Zoengsaam } & \text { zinghai } & \text { ze-zo } & \text { go } & \text { bun } & \text { siusyut } & \text { lo1. } \\
\text { Zoengsaam } & \text { only } & \text { borrow-Perf } & \text { Dem } & \text { Cl } & \text { novel } & \text { SP }
\end{array}
$$


(a) *'ZOENGSAAM only borrowed the novel. (Nobody else did).'

(b) 'Zoengsaam only borrowed THE NOVEL. (and nothing else).'

$$
\text { (focus }=\text { subject) }
$$

(focus $=$ object)

(c) 'Zoengsaam only BORROWED THE NOVEL. (He did nothing else.)'

(d) 'Zoengsaam only BORROWED the novel. (She did not buy it.)'

$$
(\text { focus }=\mathrm{VP})
$$

(focus $=\mathrm{V}$ )

Moreover, like English only, Cantonese zinghai cannot be associated with a silent focused element (see Tancredi 1990; Beaver and Clark 2003 for this property in English) (Condition 2). In (34), a second SP is inserted at the end of the second sentence to ensure that the example involves two sentences. The focus of zinghai cannot be associated with the silent DP.

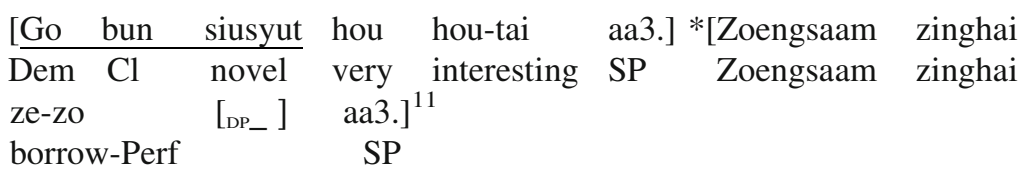

Intended: 'The novel is very interesting. Zoengsaam only borrowed THE NOVEL. [Zoengsaam did not borrow other novels.]'

One might suspect that the ungrammaticality could possibly be due to the unavailability of an anaphoric relation between the null pronoun in the second sentence and the corresponding DP in the first sentence. However, this cannot be true. If zinghai is removed, the anaphoric interpretation is perfectly fine.

Interestingly, it is possible for zinghai in the $\alpha$-part to associate with an element in the $\beta$-part, as in (36) and (37). These sentences may sound a bit odd when uttered out of the blue. A preceding question (35) is provided to improve acceptability.

Zoengsaam (zinghai) ze-zo matje aa3? (Cantonese/Question)
Zoengsaam only borrow-Perf what SP
'What is the thing $x$ such that Zoengsaam only borrowed $x$ ?'

(36) [DP Go bun siusyut] aa3, Zoengsaam zinghai ze-zo.

Dem $\mathrm{Cl}$ novel SP Zoengsaam only borrow-Perf

'Zoengsaam only borrowed the novel (and nothing else).'

(Cantonese/Ans to (35))

(37) ? [DP $\mathrm{Na}$ ben xiaoshuo ba], Zhangsan zhi jie-le.

Dem $\mathrm{Cl}$ novel SP Zhangsan only borrow-Perf

'Zoengsaam only borrowed the novel (and nothing else).'

(Mandarin/Ans to (35))

It is noted that, unlike the Cantonese example in (36), quite a number of native speakers of Mandarin find (37) marginal. I do not have a good explanation for this. However, to

\footnotetext{
11 The sentence is bad on the intended reading only. (34) is fine when zinghai focuses the verb ze-zo.
} 
the extent that Cantonese (36) is possible, the $\alpha$-part and the $\beta$-part should be components of a single sentence. Neither the parallel structure analysis nor the fragment analysis can make the correct prediction in this case. Though it is still unclear at this point why zinghai can focus an element not in its surface scope, an analysis that assumes that the $\alpha$-part and the $\beta$-part constitute a sentence is necessary. To explain the dependency, an account such as Hypothesis 1 that posits that zinghai in the $\alpha$-part c-commands the pre-SP $\beta$-part at some point of derivation seems to be necessary.

\subsubsection{Doudai test}

According to Huang and Ochi (2004), to form a "wh-the-hell" expression in Mandarin, the adverb daodi has to be associated with a wh-phrase in its c-command domain. The Cantonese counterpart, doudai, works in the same way as Mandarin daodi. (38a) and (38b) are grammatical sentences because daodi and doudai c-command 'what.'

$$
\begin{array}{llllll}
\text { a. } & \mathrm{Ni} & \text { daodi } & \text { xiwang ta hui mai } & \text { shenme? }
\end{array}
$$

'What the hell do you hope that he will buy?'

(Mandarin/(12b) in Huang and Ochi 2004)

b. Nei doudai heimong keoi wui maai matje aa3? (Cantonese) you DOUDAI hope he will buy what SP

'What the hell do you hope that he will buy?'

It is not sufficient for daodi/doudai to be associated with a wh-phrase trace in both Mandarin and Cantonese (Conditon 2). Consider the $w h$-fronting construction ${ }^{12}$ in (39).

$$
\begin{aligned}
& \text { a. * }[\text { Nei yi ben shu }]_{i} \text { ne, ta daodi } \\
& \text { which one } \mathrm{Cl} \text { book NSFP he DAODI yesterday } \\
& \text { mai-le } t_{i} \text { ? }^{13} \\
& \text { buy-Perf } \\
& \text { 'Which [the hell] book did he buy yesterday?' } \\
& \text { b. * }[\text { Bin bun syu }]_{i} \text { le, keoi doudai caamjat maai-zo } t_{i} \\
& \text { which Cl book NSFP he DOUDAI yesterday buy-Perf } \\
& \text { aa3? } \\
& \text { SP }
\end{aligned}
$$ which $\mathrm{Cl}$ book NSFP he DOUDAI yesterday buy-Perf

aa3? (Cantonese)
SP

'Which [the hell] book did he buy yesterday?'

Now what about DFC sentences? Consider (40) and (41).

12 Wh-fronting is possible in Chinese. Interested readers can refer to Wu (1999).

13 Note that the corresponding sentence without fronting the $w h$-phrase is perfectly fine.

(i) Daodi ta zuotian mai-le na yi ben shu?

DAODI he yesterday buy-Perf which one CL book

'Which [the hell] book did he buy yesterday?' 
(40)

a. [Maai-zo matje ] aa3, doudai nei -?

(Cantonese) buy-Perf what SP DOUDAI you

'What the hell did you buy?'

b. [Mai-le shenme] ne, daodi ni -? buy-Perf what SP DOUDAI you

'What the hell did you buy?'

(41) a. [Nei maai-zo matje ] aa3, doudai -?

you buy-Perf what SP DOUDAI

'What the hell did you buy?'

b. [Ni mai-le shenme] ne, daodi -?

you buy-Perf what SP DOUDAI

'What the hell did you buy?'

(Cantonese)

(Mandarin)

Such sentences are highly acceptable to native speakers of Cantonese and Mandarin. The well-formedness of these sentences, again, entails that the entire DFC sentence involves only one sentence, in which the wh-phrase occurs within the c-command domain of doudai/daodi at some point in the derivation.

\subsubsection{Polarity item conglai 'ever'}

Mandarin conglai "ever" can be licensed only by a clausemate negation following it (Progovac 1994). Cantonese cognate cungloi 'ever' displays the same pattern. The contrast below illustrates the obligatory presence of clausemate negation.

$$
\begin{array}{llccc}
\text { Keoi } & \text { cungloi } & *(\mathrm{mou}) & \text { gin-gwo } & \text { Zoengsaam. } \\
\text { he } & \text { ever } & \text { have.not } & \text { see-Exp } & \text { Zoengsaam }
\end{array}
$$

Furthermore, it is not possible to use cungloi in fragments with the negation morpheme being elided (Condition 2), as illustrated in (43). Though negation is pragmatically implied in the context (c.f. answer a and b), it is not possible to leave out the negation after "ever."

$\begin{array}{lllll}\text { Question: } & \text { Nei jicin jau-mou } & \text { gin-gwo } & \text { Zoengsaam } & \text { aa3? } \\ & \text { you before have-have.not see-Exp } & \text { Zoengsaam } & \text { SP } \\ & \text { 'Have you seen Zoengsaam before?' } & & \end{array}$

Answer:
a. Mou! Cungloi mou!
have.not ever have.not
'No. Never.'
b. Mou! *Cungloi!
have.not ever
Intended: 'No. Never.'

Interestingly, in the DFC, it is perfectly acceptable for cungloi to occur without being immediately followed by the negation marker in the $\alpha$-part. 

(44)
$\begin{array}{lllllll}\text { Mou } & \text { gin-gwo } & \text { Zoengsaam } & \text { gaa3, } & \text { ngo } & \text { cungloi. } & \text { (Cantonese) } \\ \text { have.not } & \text { see-Exp } & \text { Zoengsaam } & \text { SP } & \text { I } & \text { ever } & \end{array}$
'I have never seen Zoengsaam.'

Moreover, the acceptability is crucially dependent on the presence of negation in the pre-SP part. The removal of negation in the pre-SP part in (44) leads to ungrammaticality.

\subsubsection{Principle C violations}

Principle $\mathrm{C}$ violations arise when a referring expression is c-commanded by a co-referential element such as a pronoun. The parallel structure analysis (Hypothesis 3 ) and the fragment analysis (Hypothesis 4) predict that it should be acceptable for the referring expression and the co-referential pronoun to occur in the $\alpha$-part and the $\beta$-part, respectively, because no c-command relation between the two holds in these representations. (45) shows that the referring expression John and the pronoun keoi can be coindexed when they occur in different sentences.
(45) $\underline{\mathrm{John}_{i}}$ m-hoji caamgaa beicoi lo1. $\underline{\mathrm{Keoi}_{i j}}$ soengseon $\overline{\text { John }}$ not-can participate competition SP he believe gaa3. $\quad$ (2 sentences)
$\mathrm{SP}$
' $\mathrm{John}_{i}$ cannot participate in the competition. $\mathrm{He}_{i / j}$ believed (so).'

In contrast, ungrammaticality results when the DFC is involved, as shown in (46). The ungrammaticality is an instance of a Principle $\mathrm{C}$ violation because if the pronoun keoi is not co-referential with John, the sentence becomes acceptable.
(46) $\mathrm{John}_{i}$ m-hoji caamgaa beicoi lo1, keoi $*_{i / i}$ soengseon. (DFC) John not-can participate competition SP he believe
' $\mathrm{John}_{i}$ believed that he $*_{i / j}$ cannot participate in the competition.'

The ungrammaticality of the co-referential reading in (46) cannot be due to a c-command relation between the pronoun and the silent element after soengseon 'believe' because (45) is an acceptable sentence even when the pronoun is interpreted as John. If the DFC involves a parallel structure (i.e., Hypothesis 3) or an independent fragment (i.e., Hypothesis 4), the Principle $\mathrm{C}$ effects would be left unexplained.

\subsection{Summary}

On the basis of the connectivity tests, it can be concluded that the $\beta$-part and the $\alpha$-part of DFCs are parts of a single sentence/CP rather than two independent fragments or sentences. Reconstruction effects are consistently observed across the tests. The leftward movement account is by far the most plausible proposal among other conceivable ones. This being so, the patterning in DFCs therefore provides important 
empirical support for the claim that the functional projection hosting the SP in Chinese is head-initial. A further consequence of the head-initial CP analysis resulting from a consideration of DFCs is that even canonical word order (i.e., $\mathrm{S}-\mathrm{Aux}-\mathrm{V}-\mathrm{O}-\mathrm{SP}$ ) sentences should be derived by IP-movement around the SP. This idea will be pursued in the next section.

\section{XP Movement analysis and its constraints}

\subsection{XP movement analysis}

The head-initial CP analysis of the SP in DFCs necessitates the availability of some mechanism to guarantee surface linear word orders. The SP shows up (i) sentencemedially in the DFC sentence and (ii) sentence-finally in the CWO sentence. The proposal I would now like to make is that in both DFC and CWO sentences, an XP has to undergo movement into a C-domain SpecFocP in order to check off focus features on the functional head $\mathrm{Foc}^{0}$ (Chomsky 1995). The proposal is given as follows:

(47) XP-raising (Version 1)

a. The SP is the head of a head-initial functional projection, FP, in the $\mathrm{C}$ domain.

b. XP-raising: A Focus Phrase (FocP) is located above the FP. Its head, $\mathrm{Foc}^{0}$, has a focus feature that needs to be checked off by moving a focused XP to SpecFocP.

The FocP is assumed to be above the projection hosting the SP so as to accommodate the fact that the XP always precedes the leftmost particle in particle clusters ${ }^{14}$. In the case of particle clusters, the FP can be broken down further into several layers ${ }^{15}$. Postulating the focus feature in $(47 \mathrm{~b})$ is motivated by the focus reading triggered, as discussed in Sect. 2.3. To derive DFC sentences, the relevant focused $\mathrm{XP}$ in (48) moves to SpecFocP to fulfill the focus feature checking requirement. However, due to the Spine Constraint discussed below in Sect. 4.2, only XPs indicated by the dotted circles can be targeted for movement. Under such a view, the

\footnotetext{
14 Alternatively, one may assume that the focus feature attracting the XP is always located in the highest functional projection hosting the leftmost particle in the cluster.

15 I adopt one of Li's (2006, p. 5) proposals for dissecting the CP hosting the SPs into multiple layers. Though she is neutral about whether Chinese CPs are head-initial or head-final, her suggestion is that if they are head-initial, the structure is as follows. To derive the linear order IP PRT $\mathrm{PRT}_{2} \mathrm{PRT}_{1}$, one has to assume successive movements through the Speces of these projections.
}

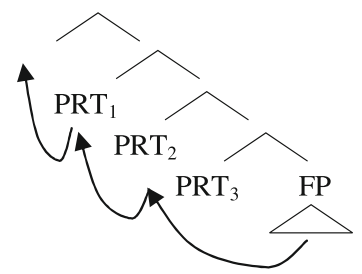


CWO sentence is a special case of XP-raising, in which the IP (or IP2 in (48)) moves to SpecFocP ${ }^{16}$. The proposal unifies the two word orders in a simple manner.

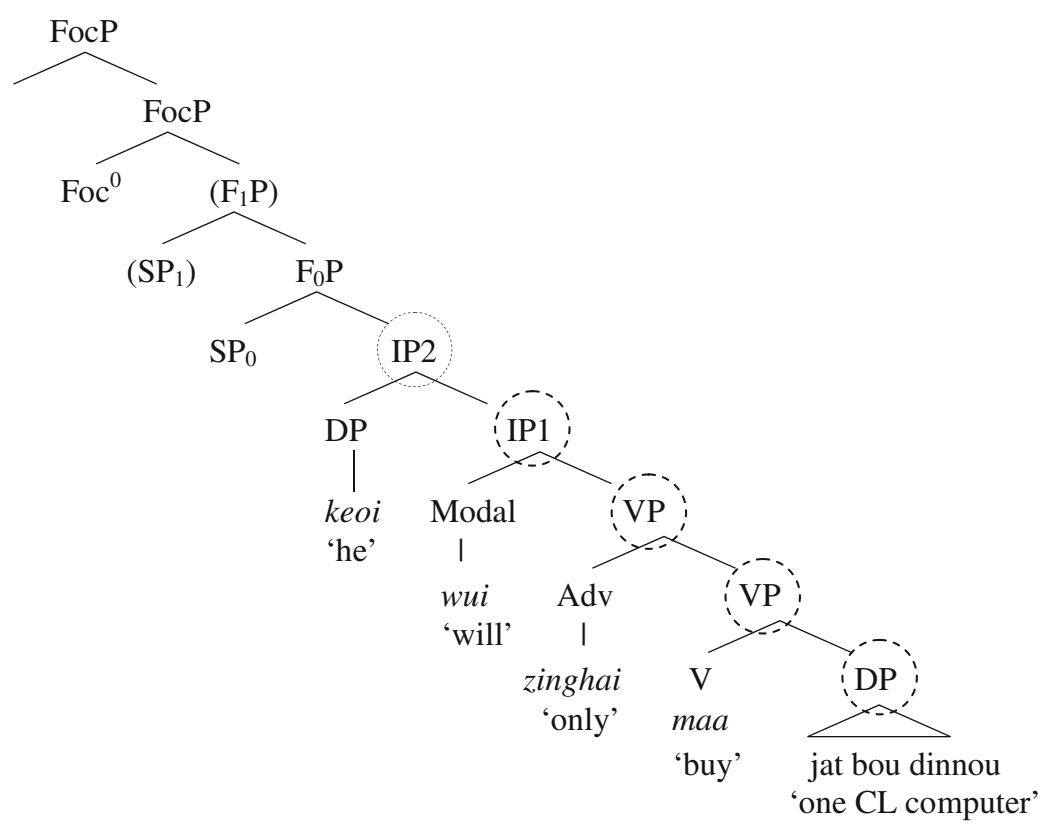

The rest of Sect. 4 is now devoted to further issues that characterize this XP-raising: (i) the Spine Constraint and (ii) pied-piping.

\subsection{Spine constraint and island constraints}

Though the $\beta$-part can be of different syntactic categories, not all constituents in the sentence can serve as the XP in the $\beta$-part; for example, the subject DP cannot occur as the $\beta$-part. As discussed in Cheung (1997, 2005), two sets of constraints restrict which XP can occur in the $\beta$-part: the Spine Constraint ${ }^{17}$ and Island Constraints.

The Spine Constraint states that no XP that is on a left branch or is dominated by a node on a left branch can occur as the $\beta$-part of a DFC. Consider (49) and the corresponding DFC sentences in (50). The underlying structure is shown in (51).

\footnotetext{
16 The IP focus-movement finds some cross-linguistic support in Italian. Samek-Lodovici (2006) analyzes Italian right dislocation as the result of two processes. First, an element is topicalized. Then the entire remnant IP moves to the specifier of a higher projection around the topic. The topic ends up at the right end of the entire sentence.

17 In Cheung (2005), the term "Strictly Left Branch Constraint" is used to refer to the Spine Constraint. 


$\begin{array}{lllllllll}\text { Keoi } & \text { wui } & \text { hou } & \text { faai } & \text { gam } & \text { se } & \text { fung } & \text { seon } & \text { lo1. } \\ \text { he } & \text { will } & \text { very } & \text { quick } & \text { GAM } & \text { write } & \mathrm{Cl} & \text { letter } & \text { SP }\end{array}$

(CWO) 'He will quickly write the letter.'
a. ??seon
lo1, keoi wui houfaaigam se fung. ${ }^{18}$
b. fung seon
lo1, keoi wui houfaaigam se.
c. se fung seon
d. houfaaigam se fung seon
lo1, keoi wui houfaaigam.
e. wui houfaaigam se fung seon lo1, keoi.
f. *keoi lo1, wui houfaaigam se fung seon.

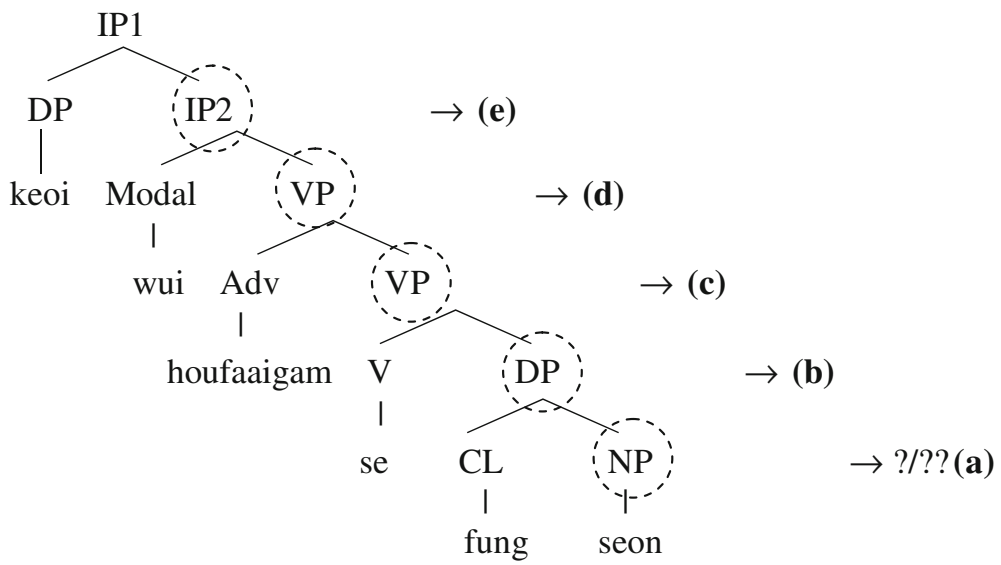

The Spine Constraint essentially allows only constituents on the "spine" (i.e., circled XPs in (51)) to be targeted for movement. Formally speaking, all those nodes on the spine are dominated exclusively by nodes that are on a non-left branch. This is very similar to the notion of "major path" alluded to in Cinque's (1993) focus projection. The Spine Constraint guarantees that DFCs exclude the movement of, for example, subject DPs, non-final adjunct clauses or preverbal PP objects. ${ }^{19}$ It should be stressed that this patterning does not result from restrictions imposed by island-like/ECP-type constraints. For example, subject DPs in Chinese can be easily relativized or topicalized (Huang 1982).

${ }^{18}$ This sentence is not as acceptable as (50b-e), quite possibly because of the heaviness of the post-SP part. The sentence can be improved if it is made shorter.

(i) Question: What has he bought?

Answer: (?) Siusyut lo1, jat bun. [as opposed to a textbook, a magazine, etc.] novel SP one $\mathrm{Cl}$.

'A novel.'

19 The term "preposition" in Chinese refers to a class of morphemes that normally take a DP complement. Semantically, they function like prepositions in English. However, Chinese prepositions are usually historically derived from verbs. They still retain some verbal properties. For example, some can take certain verbal suffixes. As a result, this class of morphemes is also referred to as "coverbs" (Li and Thompson 1981). 
There is also some evidence that the DFC is subject to Island Constraints in addition to the Spine Constraint. In (52), even though the DP 'two hamburgers' in the second conjunct is on the spine, it is not possible to target it for movement to the $\beta$-part in the DFC. This can naturally be attributed to the Coordinate Structure Constraint.

(52) * Loeng go honboubaau lo1, keoi maai-zo jat bui holok tungmaai two $\mathrm{Cl}$ hamburger $\mathrm{SP}$ he buy-Perf one $\mathrm{Cl}$ coke and 'He bought a coke and two hamburgers.'

Other types of island violations are harder to verify because they involve targeting an XP that is dominated by at least one node on the left branch, which can also be instances of a Spine Constraint violation. As a result, it is not entirely clear whether the ungrammaticality of (53) and (54) is due to the violation of the Spine Constraint, Island Constraint, or both.

$\underline{\text { Sentential Subject Constraint }}$

$\begin{array}{lllllll}* \text { Go } & \text { go gongzo aa3, } & {[\mathrm{Nei} \mathrm{m} \text { heoi }} & \text { hai jat go mingzi } \\ \text { Dem } & \mathrm{Cl} \text { seminar } & \mathrm{SP} \text { you not go } & \text { be one } \mathrm{Cl} \text { wise } \\ \text { ge } & \text { kyutding. } & & & & & \\ \text { Poss } & \text { decision }\end{array}$

'That you did not attend the seminar is a wise decision.'

$\underline{\text { Adjunct Island Constraint }}$

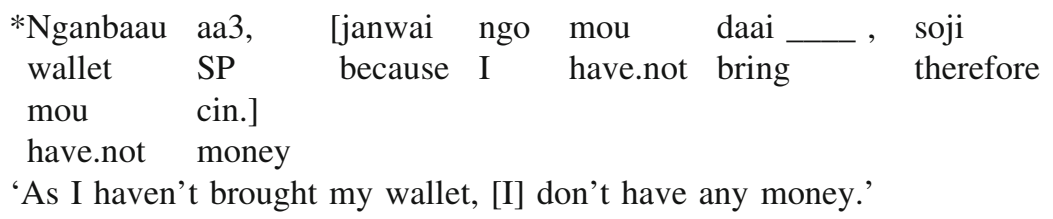

\subsection{The spine constraint}

\subsection{1 (Abstract) NSR}

To explain the Spine Constraint, the proposal in Cheung (2005), which capitalizes on parallels between the DFC and the Nuclear Stress Rule (NSR), ${ }^{20}$ will be adopted. The claim is that the set of phrases that can undergo XP-raising is essentially the same as what Reinhart $(1995,2006)$ calls the "focus set" 21 in the NSR.

\footnotetext{
${ }^{20}$ I thank Tim Stowell for drawing my attention to the parallelism.

21 I use Reinhart's $(1995,2006)$ term "focus set." However, the idea can be found in all the related works (Chomsky and Halle 1968; Cinque 1993; Zubizarreta 1994, 1998).
} 
Before comparing the DFC and NSR, let us briefly review the NSR. Drawing on insights from Chomsky and Halle (1968) and Chomsky (1971), Cinque (1993), Zubizarreta (1994, 1998), and Reinhart (1995, 2006), among others, argue that the location of the nuclear stress (NS) in languages such as English, German, and Romance languages can be determined by referring to the syntactic structure. The default NS in English normally falls on the rightmost or most deeply embedded constituent, e.g., the head noun of the object DP in a simple SVO sentence. The generalization is that with the default NS, a sentence can be ambiguous between different focus readings. This is illustrated by Reinhart's examples in $(55 \mathrm{a}-\mathrm{c})$. The NS falls on the word desk.
a. Speaker A: What's this noise? Speaker B: [F My neighbor is building a desk] (focus = IP)
b. Speaker A: What's your neighbor doing these days? Speaker B: My neighbor ${ }_{F}$ is building a desk $] \quad$ (focus $=$ VP)
c. Speaker A: What's your neighbor building? Speaker B: My neighbor is building $\left[_{\mathrm{F}}\right.$ a desk $] \quad$ (focus $=\mathrm{DP}$ )

The focus set comprises only constituents that contain the NS of the sentence (Reinhart 1995, 2006). The theory thus makes a distinction between foci that are part of the focus set and those that are not. The latter kind must be derived by shifting the stress to the appropriate word via a separate stress-shift operation (e.g., contrastive/ emphatic focus on the subject DP). Interested readers can refer to Cinque (1993), Neeleman and Reinhart (1998), and Zubizarreta (1998) among others.

The focus set in (56) resembles the set of phrases that can be subject to XP-raising in Chinese DFCs. In both cases, the constituents involved are only those on the "spine." Both exclude the subject and a left adjoined adjunct clause from being part of the focus set. Notice that the target pattern parallels what was earlier illustrated in examples (13) and (14).

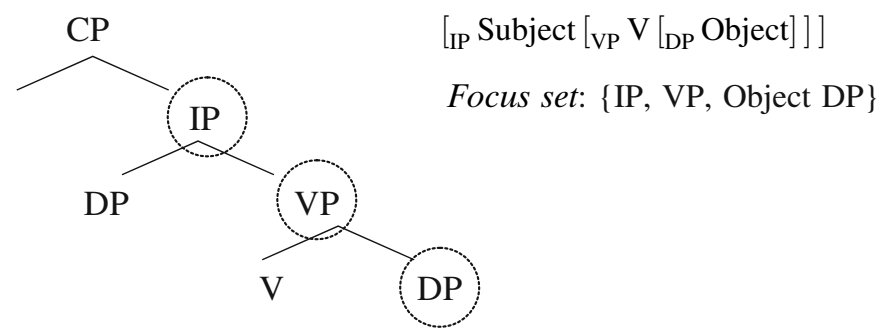

The examples in (57) show that the default NS is not compatible with readings other than those associated with the focus set, e.g. focus on the verb alone (57a) or the subject (57b).

(57) a. Speaker A: Has your neighbor bought a desk already? Speaker B: \#No, my neighbor is ${ }_{\mathrm{E}}$ building] a desk. 
b. Speaker A: Who is building a desk?

Speaker B: \#[F My neighbor $]$ is building a desk.

The parallelism motivates a unified analysis of both phenomena because, on the one hand, the two sets of XPs seem strikingly similar, and on the other hand, they both give rise to focus readings, as the question/answer diagnostic has shown.

As Cantonese lacks NS (Wong et al. 2005), the NSR has to be decoupled from NS to capture the parallel between the NSR and the Spine Constraint. I propose that the NSR should be recast as an abstract rule of focus assignment based on syntactic structure, which I will call the Abstract NSR ${ }^{22}$ (ANSR). The focus set members of a sentence are defined as the constituents that contain the most deeply embedded word. How the focus set is overtly marked is, however, language-dependent. In English, the focus set is associated with the NS on the most embedded word and can be left in-situ (i.e., no movement of the focused phrase) prior to PF. In contrast, Chinese can highlight the constituents of the focus set by moving them syntactically in the $\mathrm{DFC}^{23}$. The functional head $\mathrm{Foc}^{0}$ mentioned in the last section only attracts members of the focus set, resulting in the Spine Constraint. As the ANSR is no longer tied to NS, I propose the Dislocation Focus Projection Rule (58) in order to identify the focus set. The F-marking notation is used to indicate focus projection (c.f. Selkirk 1996).

(58) Dislocation Focus Projection Rule

a. Basic F-Assignment Rule: The most embedded word on the major path is F-marked.

b. F-Projection Rule: F-marking of a phrase/head licenses the F-marking of the phrase containing it.

(59) The focus set comprises all and only F-marked constituents.

I assume in the spirit of Cinque (1993) that the most embedded word is inherently F-marked. Essentially, all phrases containing an F-marked element can be F-marked as well. Exactly which F-marked phrase is the focused phrase is determined by the context.

The identification of the members of the focus set is illustrated using (49), repeated as (60). First, the Basic F-Assignment Rule entails that the head noun 'letter' is F-marked. The recursive application of the F-Projection Rule to phrases dominating the DP gives rise to the set of F-marked phrases. The algorithm correctly excludes anything not on the major spine.

\footnotetext{
22 The term "Abstract NSR" is admittedly a misnomer because the formulation does not really refer to NS. Yet, for the sake of convenience, I use the term in this paper.

23 A similar proposal is found in $\mathrm{Xu}$ (2004). By comparing different word orders, Xu argues that "the sentence-final position, also the most deeply embedded position on the recursive side of branching, is the default position for informational focus in [Mandarin] Chinese.”
} 
(60)

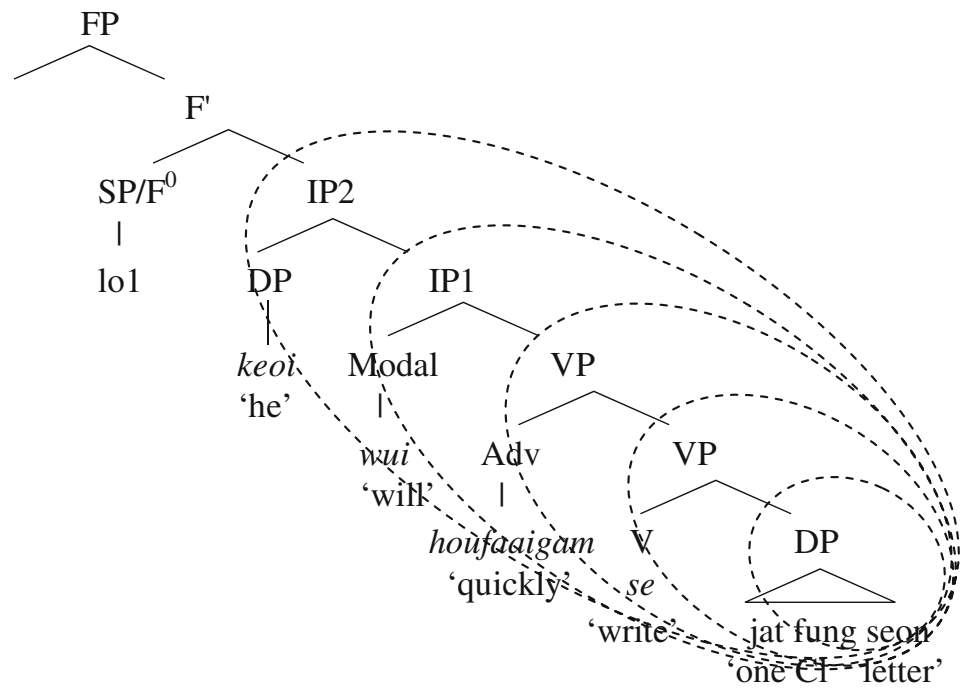

\subsubsection{Metrical invisibility}

Another reason for connecting the Spine Constraint and the NSR is that both phenomena are sensitive to what Zubizarreta calls the "metrical invisibility" 24 in the computation of the focus set. Previous studies on NS (Ladd 1980; Gussenhoven 1984; Selkirk 1984, 1995; Rochemont 1986; Zubizarreta (1998)) note a systematic exception to the assignment of NS. Descriptively, when the rightmost word is anaphoric to a discourse antecedent or is given information, it does not bear the NS. Here are some examples taken from Zubizarreta (1998, pp. 47-48). The NS falls on the capitalized word.

(61) Mary walked in.

John KISSED her.

(62) Talking about the lid, did you take the lid OFF it?

In the examples above, the NS is assigned to the rightmost (capitalized) word before the anaphoric phrases (e.g., the pronouns 'her' and 'it'). Zubizarreta's claim is that although the NS does not occur on the rightmost word, it still signals information focus. Such observations have led to the following rule in the application of the NSR.

\footnotetext{
24 "Metrical invisibility" is a term introduced by Zubizarreta (1998). Some other works refer to similar phenomenon as "deaccenting."
} 
(63) The metrically invisible constituents for the NSR in English and German are defocalized constituents and anaphoric constituents, as well as empty categories (the latter are metrically invisible in all languages). (Zubizarreta 1998, p. 72)

In effect, defocalized constituents, anaphoric constituents and empty categories become irrelevant in the computation of the NS in languages such as English.

Cheung (2005) identifies a similar, counterpart patterning in Chinese DFCs. Elided structures are found to be irrelevant to the computation of the focus set in a DFC. The application of deletion to a sentence opens up possibilities of moving XPs that are not available before applying the deletion. For example, the Spine Constraint disallows elements such as preverbal PP objects or phrases inside adjunct clauses from being the target of XP-raising because these phrases are not on the spine. Consider (64). The illicit movement is schematized in (65a), where [B C] represents an adjunct clause ${ }^{25}$ or a $\mathrm{PP}^{26}$ Surprisingly, dislocating these elements becomes significantly improved or perfect when dislocation is accompanied by the deletion of everything coming after the dislocated part in the corresponding nondislocated sentence (i.e., D E in (65b)). In particular, D and E must be elided altogether. Otherwise, the dislocation is still bad (65c).

(64)

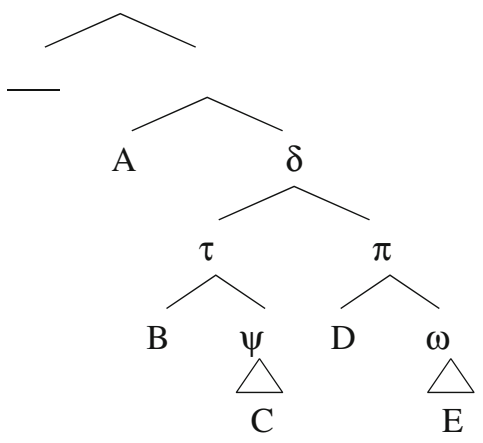

Key: $\mathrm{A}=\mathrm{SP}$

(i) If "DE" is NOT elided, Focus set: $\{\delta, \pi, \omega, E\}$

(ii) If " $\mathrm{D} E$ " is elided, Focus set: $\{\Psi, \tau, \omega\}$
a. A $\left[\begin{array}{ll}\mathrm{B} & \mathrm{C}\end{array}\right.$
$\mathrm{D} \mathrm{E} \rightarrow *$
$\mathrm{C}_{i}, \mathrm{~A}$
b. $\mathrm{A} \quad\left[\begin{array}{ll}\mathrm{B} & \mathrm{C}\end{array}\right]$
c. $\mathrm{A}[\mathrm{B} \quad \mathrm{C}]$
$\mathrm{B}-\mathrm{E}$
$\mathrm{C}_{i}, \quad \mathrm{~A}$
$\mathrm{D} \mathrm{E} \rightarrow *$
$\mathrm{C}_{i}, \mathrm{~A} \quad\left[\begin{array}{ll}\mathrm{B} & t_{i}\end{array}\right]$
$\begin{array}{ll}D & E \\ Đ & E \\ D & E\end{array}$

The actual examples exhibiting the pattern in (65) are given below. As sentences with dislocation and ellipsis may sound odd out of the blue, question/answer contexts are provided for improved acceptability. The (a) sentences involve the dislocation of elements not part of/on the spine. As predicted, they are bad. In the (b) sentences, ellipsis applies (indicated by strikeout), and the sentences become good.

\footnotetext{
${ }^{25}$ Let us assume that if [B C] is an adjunct clause, $\mathrm{C}$ is the object DP in the adjunct clause, and B is the rest of the adjunct clause.

${ }^{26}$ Let us assume that if [B C] is PP, B is the preposition, and $\mathrm{C}$ the preposition object.
} 
Further, only ellipsis of the kind described in (65b) is able to salvage the sentence. Otherwise, ungrammaticality results, as in the (c) sentences.

\section{VP in Adjunct Clause-'because'-clause in the preverbal position}

\begin{tabular}{|c|c|c|c|c|c|c|}
\hline Question: & $\begin{array}{l}\text { Keoi hai } \\
\text { he be } \\
\text { mou } \\
\text { have.not }\end{array}$ & $\begin{array}{l}\text { i } \quad \text { janwai } \\
\text { because } \\
\text { jingsing } \\
\text { promise }\end{array}$ & $\begin{array}{l}\text { singkeijat } \\
\text { Sunday } \\
\text { lei } \\
\text { come }\end{array}$ & $\begin{array}{l}\text { jiu } \\
\text { need } \\
\text { aa3? } \\
\text { SP }\end{array}$ & $\frac{\mathrm{zou}}{\mathrm{do}}$ & $\frac{\text { matje] }}{\text { what }}$ \\
\hline
\end{tabular}

'What is thing $x$ such that he didn't promise to come because he needs to do $x$ on Sunday?'

Answer: Keoi hai [janwai singkeijat jiu caamgaa gaauwui he be because Sunday need participate church ge zeoiwui], soji mou jingsing lei lo1 (CWO) Poss gathering so have.not promise come SP

'Several people did not promise to come because they had to participate in a church gathering on Sunday.'

a. ??Caamgaa gaauwui ge zeoiwui lo1, keoi hai [janwai participate church Poss gathering SP he be because singkeijat jiu __ ], soji mou jingsing lei Sunday need so have.not promise come

b. Caamgaa gaauwui ge zeoiwui lo1, keoi hai [janwai participate church Poss gathering SP he be because singkeijat jiu _ ], joji mou jingsing tei. Sunday need so have.not promise come
c. * Jiu caamgaa gaauwui ge zeoiwui lo1, keoi hai need participate church Poss gathering SP he be [janwai singkeijat __ ], soji mou jingsing tei. because Sunday so have.not promise come

\section{$\underline{\text { Preverbal PP Object }}$}

$\begin{array}{lllll}\text { Question: } & \text { Keoi hai geido dim lei-dou } & \text { aa3? } \\ \text { he at how.many o'clock } & \text { come-arrive } & \text { SP } \\ \text { 'At what time did he arrive?' } & & \end{array}$

Answer: Keoi hai saam dim lei-dou gaa3. (CWO) he at three o'clock come-arrive SP

'He arrived at three o'clock.'
a. *Saam dim lo1, keoi hai three o'clock SP he at come-arrive
b. Saam dim lo1, keoi hai three o'clock SP he at
c. (not applicable)
teider.
come-arrive

The ungrammaticality of the (a) and (c) sentences is unlikely to be due to the relative heaviness of the post-SP parts. Even if the pre-SP part is made very heavy, 
the sentence is still not acceptable. Also, (b) and (c) are very similar in relative weight; yet their acceptability differs significantly.

These observations may initially seem puzzling because it is not clear why the specific kind of ellipsis can license the dislocation. ${ }^{27}$ This is where Zubizarreta's metrical invisibility condition provides an important clue to explaining the phenomenon. The condition makes empty categories invisible, because they are generally anaphoric in nature. If the structure that exclusively dominates elided elements is invisible in the computation of the ANSR (i.e., the F-marking procedure), some elements that are formerly not part of the focus set in the (b) sentences can become a member of the focus set in the adjusted spine. Given metrical invisibility, the focus sets of (65) are re-calculated as follows.

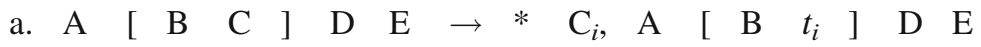 Focus set: $\{\delta, \pi, \omega, \mathrm{E}\}$
b. $\mathrm{A} \quad\left[\begin{array}{lll}\mathrm{B} & \mathrm{C}\end{array}\right] \mathrm{D}-\mathrm{E} \rightarrow$
$\mathrm{C}_{i}, \quad \mathrm{~A} \quad\left[\begin{array}{llllll}\mathrm{B} & t_{i}\end{array}\right] \mathrm{Ð}-\mathrm{E}$ Focus set: $\{\delta, \tau, \psi, \underline{\mathrm{C}}\}$

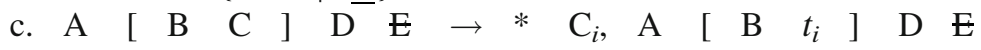 Focus set: $\{\delta, \pi, \mathrm{D}\}$

The adjusted focus sets correctly predict that $(68 \mathrm{~b})$ is accepted but $(68 \mathrm{a}, \mathrm{c})$ are rejected. (69) is the illustration of the example in (66). The circled nodes in (69b) can undergo movement.

a. Original Structure

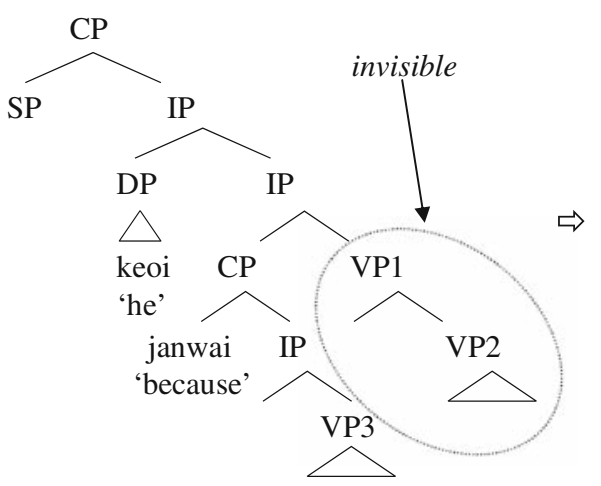

b. Structure Visible to ANSR

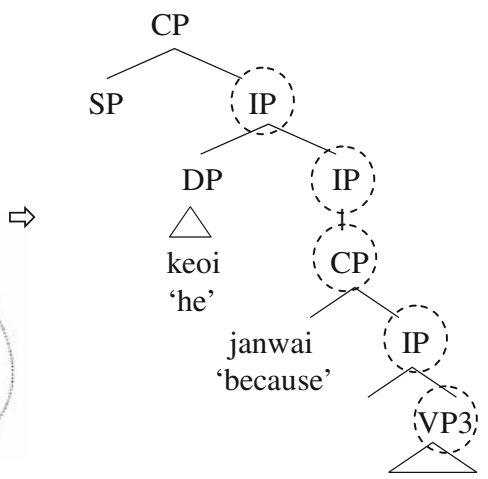

In connection with what has been described here in DFCs, it should be pointed out that the effect of syntactic operations on the focus set is certainly not unique to Chinese DFCs. Zubizarreta (1998) argues that in Spanish, SVO/VSO sentences can be reordered as VOS in order to put the focused subject in a position to receive the

\footnotetext{
27 The rescue of an illicit movement with ellipsis may remind us of the repair of island violation under sluicing (Chung et al. 1995; Merchant 2001, 2008). In sluicing, the deletion is applied to the site of violation, which is an important property in the explanation of the repair of island violation. However, in dislocation, the ellipsis is not applied to the site of violation. So I assume that the two phenomena are actually quite different.
} 
NS, referring to this as "prosodically-motivated movement." For example, to answer the question "Who gave you the bottle of wine?", Zubizarreta observes that one can only say (70c) but not (70a) or (70b).
a. \#María me regaló la botella de vino. María to-me gave the bottle of wine.
b. \#Me regaló María la botella de vino.
c. Me regaló la botella de vino $\{\underline{\text { María }}\}$.

(SVO)

Essentially, everything below the subject DP has to be relocated and moved to the left in order to allow the NS to fall on the subject. This reordering of the words results in the subject DP being the most deeply embedded element in the structure and receiving the focus. A similar point is made by Ishihara (2001), in a study of Japanese, in which scrambling is reported to make a difference in the computation of the focus set. Consider $(71 \mathrm{a}, \mathrm{b})$. (The accent mark indicates the position of the NS.) It is assumed that the verb undergoes head-movement to I.
a. [IP Taro-ga [vP2 kyoo [VP1 [DP hón-o] $\left.\left.t_{i}\right]\right]$ katta $\left.\left.{ }_{i}\right]\right]$ (non-scrambled) Taro-Nom today Focus set: $\{\mathrm{OBJ}, \mathrm{VP} 1, \mathrm{VP} 2, \mathrm{IP}\}$
b. [IP2 hon-o ${ }_{j i}\left[\mathrm{IP} 1\right.$ Taro-ga $\left[\left[_{\mathrm{vP} 2}\right.\right.$ kyóo $\left.\left.\left.\left.\left[{ }_{\mathrm{VP} 1} t_{j} t_{i}\right]\right] \mathrm{katta}_{i}\right]\right]\right]$ (scrambled) book-Acc Taro-Nom today bought
Focus Set: $\{$ ADV, VP2, IP1, IP2 $\}$ (but not VP1)

In the non-scrambled sentence (71a), the NS falls on the pre-verbal object because the object is the most deeply embedded element in the sentence, and the adverb kyoo is not part of the focus set in isolation from other material following it. However, if the object DP is scrambled, as shown in (71b), the adverb becomes the most deeply embedded element, receives the NS and is admitted as a member of the focus set.

\subsubsection{Pied-piping}

Another aspect of the DFC which requires some further remarks is the size and identity of the XP which undergoes movement as the $\beta$ element. Although the DFC clearly entails different focus interpretations depending on the XP moved to SpecFP, the focused constituent and the moved XP are not always congruent. The example in (13) and (14) is modified below as (72). The focused constituent is the object DP. In (72a,c,d), the moved XP (bracketed) is larger than the object DP (underlined), and they are equally acceptable as answers to the question.

(72) Question: What will he buy?

Answer:

a. [Keoi wui maai jat bou dinnou ] lo1.
he will buy one $\mathrm{Cl}$ computer SP
b. [Jat bou dinnou ] lo1, keoi wui maai.
one $\mathrm{Cl}$ computer SP he wui buy

(Object DP) 

c. [maai jat bou dinnou ] lo1, keoi wui. buy one $\mathrm{Cl}$ computer $\mathrm{SP}$ he will
$\begin{array}{clllll}\text { d. [wui maai jat bou dinnou ] lo1, keoi. } & \text { la } \\ \text { will buy one } & \mathrm{Cl} & \text { computer } & \text { SP he }\end{array}$

The pattern suggests that even when the larger constituent gets moved along with the focused constituent inside it, the sentence is still considered as an acceptable answer. In other words, as long as the moved XP contains a member of the focus set, the DFC sentence is fine. This is reminiscent of the phenomenon of pied-piping in wh-interrogatives. Pied-piping has also been independently noted in focus-movement in Hungarian (Horvath 1986, 2005; Kenesei 1998). In the following examples, the underlined words constitute the semantic focus (capitalized words), but it is a larger bracketed XP containing the focused constituent ${ }^{28}$ which moves to the preverbal focus position.

[Taken from Horvath (1986, p. 143 (note 2))]

$\begin{array}{llll}\text { (73) Attila } & \text { [MÁRI } & \begin{array}{l}\text { kutyájatól] } \\ \text { dog-hers-from }\end{array} & \text { felt } \\ \text { Attila } & \text { MARY }\end{array}$

'It was MÁRY'S dog that Attila was afraid of.'

[Taken from Horvath (2005)]

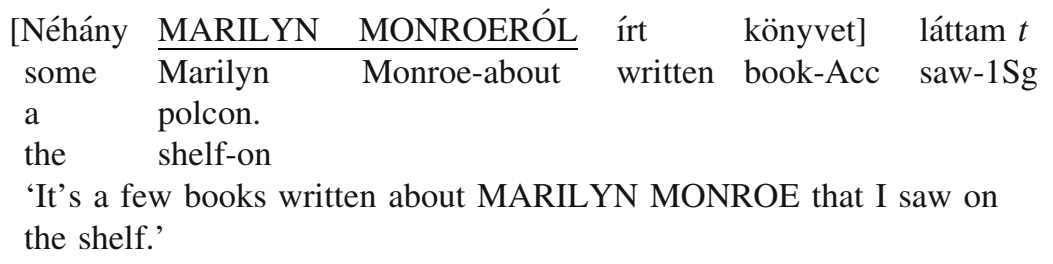

Due to the possibility of pied-piping, the characterization of XP-raising in (47) must be revised. It is necessary to distinguish the moved constituent and the semantically focused constituent. XP-raising is revised as follows to accommodate pied-piping.

(75) XP-raising (Version 2)

a. The SP is the head of a head-initial functional projection, FP, in the C domain.

b. XP-raising: A Focus Phrase (FocP) is located above the FP. Its head, $\mathrm{Foc}^{0}$, has a focus feature that needs to be checked off by moving the F-marked XP that either is the focus itself or contains the focus to $\mathrm{SpecFocP}$.

\footnotetext{
${ }^{28}$ Horvath (1986) characterizes the focused constituent as follows to accommodate pied-piping. "A constituent (other than V or a projection of V) can be interpreted as the FOCUS of its clause in Hungarian if, and only if, it itself occupies an immediately pre-verbal position, or is contained in a phrase that does so.” (boldface mine).
} 
The relation between the actual semantic focus and the moved XP is mediated by the pied-piping mechanism. Although the discussion so far has been referring to the set of phrases qualifying for movement in DFCs as the "focus set", these constituents actually do not have to be the semantic focus, as long as the semantic focus is contained within them.

Before closing this section, I want to mention one final consequence of the analysis presented here. (75) above may seem to entail that CWO sentences which involve IP-raising also receive a focus reading. This would not be a desired result. Obviously, CWO sentences are compatible with both focus and non-focus interpretations (e.g., out-of-the-blue uses). This being so, how may we account for the non-focus interpretation of CWO sentences? Here I will note very briefly a way to deal with the issue. I propose that while (75) only explains the focus interpretation of CWO sentences (and DFCs), the movement of the IP in non-focus interpretations could potentially be driven by other motivations. One possibility is in fact defocusing. Recall that IP movement has been attributed to defocalization in Simpson and $\mathrm{Wu}$ (2002) with regard to kong-final sentences in Taiwanese. I suggest that in the non-focus interpretation, an IP in CWO sentences obligatorily moves into another functional projection, SpecYP, for purposes of defocusing. In such a possible account, the movement of the IP in CWO sentences would actually be caused by different triggers depending on whether or not a focus interpretation is involved.

\section{Conclusion}

The patterns discussed in this paper have revealed a number of important properties of Chinese clausal structure and movement driven by focus. Having shown with various connectivity tests that the $\alpha$-part and the $\beta$-part in DFCs are integral parts of a single sentence, the occurrence of SPs between these two parts provides good empirical support for the following conclusions: (i) CPs in Chinese are head-initial, and (ii) overt material preceding an SP occurs in such a position due to movement from below the SP. The conclusion in (i) in turn makes Chinese more consistent with regular VO language typology. Further, the movement of an XP to the $\beta$-part of a DFC is sensitive to focus and constrained by the Spine Constraint and Island Constraints. The former constraint has been suggested to be the syntactic manifestation of focus projection as it also occurs in the application of the NSR, on the basis of the striking resemblance with the focus projection and metrical invisibility in the NSR.

Acknowledgements The analysis of the DFC is based on my UCLA MA thesis. I am indebted to the inspiration from and discussion with Tim Stowell, Daniel Büring, Anoop Mahajan, and Dominique Sportiche. I have benefited greatly from the discussion with Francesca Del Gobbo, Victor Manfredi, Andrew Nevins, Thomas Lee, Dylan Tsai, and Michael Wagner. I am grateful for the comments from an anonymous reviewer. Special thanks go to Andrew Simpson for his suggestions and help and to James Huang for his encouragement. The preliminary version of this paper was presented at UCLA Syntax/ Semantics seminar and the First International Conference on East Asian Linguistics held at the University of Toronto on November 10-12, 2006. I also thank those audiences for comments and suggestions. 
Open Access This article is distributed under the terms of the Creative Commons Attribution Noncommercial License which permits any noncommercial use, distribution, and reproduction in any medium, provided the original author(s) and source are credited.

\section{References}

Beaver, David, and Brady Clark. 2003. Always and only: Why not all focus sensitive operators are alike. Natural Language Semantics 11: 323-362.

Chao, Yuen Ren. 1968. A grammar of spoken Chinese. Berkeley: University of California Press.

Chen, Qi-hong. 1995. Gu Hanyu zhuwei yiweiju ji qi xiangguan wenti [Subject-predicate dislocation in Classical Chinese and its related issues]. Xuzhou Shifan Xueyuan Xuebao, 3: 69-73.

Cheng, Lisa. 1991. On the typology of Wh-questions. PhD diss., MIT.

Cheng, Lisa. 1994. Wh-words as polarity items. In Chinese Languages and Linguistics II. Symposium Series of Institute of History and Philology, ed. Ren-Kui Li, 615-640. Taiwan: Academia Sinica.

Cheung, Yam Leung (Lawrence). 1997. A study of right dislocation in Cantonese. M.Phil. thesis, Chinese University of Hong Kong.

Cheung, Y.-L. Lawrence. 2005. Syntax and semantics of dislocation focus construction in Cantonese. MA thesis, UCLA.

Cheung, Y.-L. Lawrence. 2008. Obligatory XP-raising in Chinese. In Toronto Working Papers in Linguistics 28 (Proceedings of the International Conference on East Asian Linguistics), ed. Sarah Clarke, Manami Hirayama, Kyumin Kim, and Eugenia Suh, 15-28. Toronto: University of Toronto, Department of Linguistics.

Chomsky, Noam. 1971. Deep structure, surface structure and semantic interpretation. In Semantics: An interdisciplinary reader in philosophy, linguistics and psychology, ed. Danny Steinberg and Leon Jakobovits, 183-216. Cambridge: Cambridge University Press.

Chomsky, Noam, and Morris Halle. 1968. The sound pattern of English. Cambridge, MA: MIT Press. Chomsky, Noam. 1995. The Minimalist Program. Cambridge, MA: MIT Press.

Chomsky, Noam. 2001. Derivation by phase. In Ken Hale: A life in language, ed. Michael Kenstowicz, 1-52. Cambridge, MA: MIT Press.

Chung, Sandra, William Ladusaw, and James McCloskey. 1995. Sluicing and logical form. Natural Language Semantics 3: 239-282.

Cinque, Guglielmo. 1993. A null theory of phrase and compound stress. Linguistic Inquiry 24: 239-297.

Gussenhoven, Carlos. 1984. On the grammar and semantics of sentence accents. Dordrecht: Foris.

Horvath, Julia. 1986. Focus in the theory of grammar and the syntax of Hungarian. Dordrecht: Foris. Horvath, Julia. 2005. Separating 'focus movement' from focus. Ms., Tel-Aviv University.

Hsieh, Feng-fan. 2005. Atoms and particles. Ms., MIT.

Hsieh, Feng-fan, and Rint Sybesma. 2008. Generative syntax and sentence-final particles in Chinese. In Contemporary linguistic theories and related studies on Chinese, ed. Yang Shen and Shengli Feng, pp. 364-374. Beijing: The Commercial Press.

Huang, C.-T. James. 1982. Logical relations in Chinese and the theory of grammar. PhD diss., MIT.

Huang, C.-T. James, and Masao Ochi. 2004. Syntax of the hell: Two types of dependencies. In Proceedings of the 34th Conference of the North Eastern Linguistic Society (NELS), ed. Keir Moulton and Matthew Wolf, 279-293. Amherst: University of Massachusetts GLSA.

Ishihara, Shinichiro. 2001. Stress, focus, and scrambling. In A few from Building E-39, MIT Working Papers in Linguistics 39, ed. Elena Guerzoni and Ora Matushansky, 151-185. Cambridge: MIT Department of Linguistics and Philosophy.

Kayne, Richard. 1994. The antisymmetry of syntax. Cambridge, MA: MIT Press.

Kenesei, István. 1998. On the syntactic options of focus. Ms., University of Delaware, Newark.

Kiss, Katalin. 1998. Identificational focus versus information focus. Language 74: 245-273.

Ladd, Robert. 1980. The structure of intonational meaning. Bloomington and London: Indiana University Press.

Law, Sam-Po. 1990. The syntax and phonology of Cantonese sentence-final particles. PhD diss., Boston University.

Law, Ann. 2003. Right dislocation in Cantonese as a focus-marking device. In University College London Working Papers in Linguistics 15, ed. Ad Neeleman and Reiko Vermeulen, 243-275. London: University College London, Department of Phonetics and Linguistics.

Law, Ann. 2004. Sentence-final focus particles in Cantonese. PhD diss., University College London. 
Leung, Chung-Sum. 2005. A study of the utterance particles in Cantonese as spoken in Hong Kong. The Language Information Sciences Research Center, City University of Hong Kong, Hong Kong.

Li, Y.-H. Audrey. 1990. Order and constituency in Mandarin Chinese. Dordrecht: Kluwer.

Li, Boya. 2006. Chinese final particles and the syntax of the periphery. Utrecht: LOT Landelijke Onderzoekschool Taalwetenschap.

Li, Charles, and Sandra Thompson. 1974. Historical change of word order: A case study in Chinese and its implications. In Historical Linguistics, ed. John Anderson and Charles Jones, 199-217. Amsterdam: North Holland.

Li, Charles, and Sandra Thompson. 1981. Mandarin: A functional reference grammar. Berkeley and Los Angeles: University of California Press.

Liang, Yuan. 2002. Dislocation in Cantonese: Sentence form, information structure, and discourse function. PhD diss., University of Hong Kong.

Lu, Jian-ming. 1980. Hanyu kouyu jufali de yiwei xianxiang [Dislocation in the syntax of colloquial Mandarin Chinese] (in Chinese). Zhongguo Yuwen 1: 28-41.

Matthews, Stephen, and Virginia Yip. 1994. Cantonese: A comprehensive grammar. London: Routledge.

Merchant, Jason. 2001. The syntax of silence: Sluicing, islands, and the theory of ellipsis. Oxford: Oxford University Press.

Merchant, Jason. 2008. Variable island repair under ellipsis. In Topics in ellipsis, ed. Kyle Johnson, 132-153. Cambridge: Cambridge University Press.

Moro, Andrea. 2000. Dynamic asymmetry. Cambridge, MA: MIT Press.

Mulder, René, and Rint Sybesma. 1992. Chinese is a VO language. Natural Language and Linguistic Theory 10: 439-476.

Neeleman, Ad, and Tanya Reinhart. 1998. Scrambling and the PF interface. In The projection of arguments, ed. M. Butt and W. Gueder, 309-353. Stanford: CSLI.

Nunes, Jairo. 2004. Linearization of chains and sideward movement. Cambridge, MA: MIT Press.

Packard, Jerome, and Ziqiang Shi. 1986. The grammaticalization of a 'post-sentential' slot in colloquial Peking Mandarin. Paper presented at the 19th Annual Conference on Sino-Tibetan Languages and Linguistics, Ohio State University.

Potts, Christopher. 2005. The logic of conventional implicatures. Oxford: Oxford University Press.

Potts, Christopher. 2007. Conventional implicatures, a distinguished class of meanings. In the Oxford handbook of linguistic interfaces, ed. Gillian Ramchand and Charles Reiss, 475-501. Oxford: Oxford University Press.

Progovac, Ljiljana. 1994. Negative and positive polarity: A binding approach. Cambridge: Cambridge University Press.

Reinhart, Tanya. 1995. Interface strategies. UiL OTS Working Papers of Theoretical Linguistics 95-002. Utrecht: Utrecht Institute of Linguistics, Utrecht University.

Reinhart, Tanya. 2006. Interface strategies: Optimal and costly computations. Cambridge, MA: MIT Press.

Rizzi, Luigi. 1997. The fine structure of the left periphery. In Elements of grammar, ed. Liliane Haegeman, 281-337. Dordrecht: Kluwer.

Rochemont, Michael. 1986. Focus in generative grammar. Amsterdam: John Benjamins.

Rooth, Mats. 1996. Focus. In The handbook of contemporary semantic theory, ed. Shalom Lappin, 271-297. Oxford: Blackwell.

Samek-Lodovici, Vieri. 2006. When right dislocation meets the left-periphery. Lingua 116: 836-873.

Selkirk, Elisabeth. 1984. Phonology and syntax: The relation between sound and structure. Cambridge, MA: MIT Press.

Selkirk, Elisabeth. 1995. Sentence prosody: Intonation, stress, and phrasing. In The handbook of phonological theory, ed. John A. Goldsmith, 550-569. Cambridge, MA, and Oxford, UK: Blackwell.

Simpson, Andrew, and Zoe Wu. 2002. IP-raising, tone sandhi and the creation of sentence-final particles. Journal of East Asian Linguistics 11: 67-99.

Siu, Po-on. 1986. On the relationships between final particles and wh-movement: mappings DS to SS in Chinese. MA thesis, University of Illinois at Urbana-Champaign.

Sun, Chao-Fen, and Talmy Givón. 1985. On the so-called SOV word order in Mandarin Chinese: A quantified text study and its implications. Language 61 (2): 329-351.

Sybesma, Rint. 1999. Overt wh-movement in Chinese and the structure of CP. In Selected papers from the Fifth International Conference of Chinese Linguistics, ed. H.-S. Wang, F.-F. Tsai, and C.-F. Lien, 279-299. Taipei: The Crane Publishing Co. 
Tancredi, Christopher. 1990. Syntactic association with focus. In Proceedings from the first meeting of the Formal Linguistic Society of Mid-America, ed. Denise Meyer, Satoshi Tomioka, and Leyla Zidani-Eroglu, 289-303. Madison: University of Wisconsin

Tsai, W.-T. Dylan. 1994. On economizing the theory of A-bar dependencies. PhD diss., MIT.

Wong, W. Y. P., Marjorie K.-M. Chan, and Mary E. Beckman. 2005. An autosegmental-metrical analysis and prosodic annotation conventions for Cantonese. In Prosodic typology: The phonology of intonation and phrasing, ed. Sun-Ah Jun, 271-300. Oxford: Oxford University Press.

Wu, Jianxin. 1999. A Minimalist account of quantification in Chinese. PhD diss., University of Maryland.

Xu, Liejiong. 2004. Manifestation of informational focus. Lingua 114: 277-299.

Yang, Feng-xian, and Qing-zhi Yang. 2002. Yiwei: Guhanyu kouyu yuti de yufa tezheng [Inversion: Grammar trait of colloquialism of the Archaic Chinese]. Journal of Beihua University (Social Sciences) 3(4): 67-70.

Zubizarreta, Maria L. 1994. On some prosodically governed syntactic operations. In Paths towards universal grammar: Studies in honor of Richard S. Kayne, ed. G. Cinque, J. Koster, J.Y. Pollock, L. Rizzi, and R. Zanuttini, 473-486. Washington: Georgetown University Press.

Zubizarreta, Maria L. 1998. Prosody, focus, and word order. Cambridge, MA: MIT Press. 